\title{
Comparative Transcriptome Analysis of Genes Involved in Penicillium Chrysogenum Induced Resistance to Root-knot Nematode in Tomato
}

\section{Mengyue Zhang}

Shenyang Agricultural University https://orcid.org/0000-0002-2000-4362

\section{Aatika Sikandar}

Shenyang Agricultural University

\section{Xiaofeng Zhu}

Shenyang Agricultural University

\section{Yuanyuan Wang}

Shenyang Agricultural University

Xiaoyu Liu

Shenyang Agricultural University

\section{Haiyan Fan}

Shenyang Agricultural University

\section{Yuanhu Xuan}

Shenyang Agricultural University

\section{Lijie Chen}

Shenyang Agricultural University

Yuxi Duan ( $\nabla$ duanyx6407@163.com )

Nematology Institute of Northern China, Shenyang Agricultural University, No.120 Dongling Road, Shenyang 110866, China https://orcid.org/0000-0002-7392-1084

\section{Research article}

Keywords: Tomato, Meloidogyne incognita, Penicillium chrysogenum, induced resistance, transcriptome analysis, RNA-seq

Posted Date: December 4th, 2020

DOI: https://doi.org/10.21203/rs.3.rs-117883/v1

License: (c) (1) This work is licensed under a Creative Commons Attribution 4.0 International License.

Read Full License 


\title{
Comparative transcriptome analysis of genes involved in Penicillium chrysogenum induced resistance to root-knot nematode in tomato
}

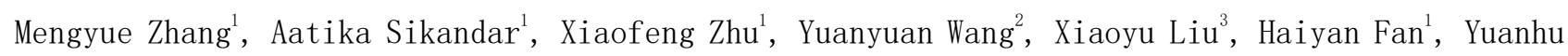
Xuan $^{4}$, Lijie Chen ${ }^{1}$, Yuxi Duan ${ }^{1 *}$

\begin{abstract}
Background: Tomato root-knot nematode is a soil-borne disease caused by Meloidogyne incognita. Enhancement of natural plant-defense mechanisms to provide resistance against pathogens may be a promising alternative environmentally friendly nematode management approach. Recently, the biocontrol effect against different pathogens in the presence of Penicillium chrysogenum has been reported in a wide range of plants and pathogens. For understanding the molecular mechanisms of the resistance induced by P. chrysogenum Snef1216 to RKN, transcriptomes of inducer control 'IRCK' (induced by Snef1216 only) and pathogen + inducer 'IRN' were compared to those of control groups, namely negative control 'CKCK' (no inoculum), pathogen control 'CKN' (inoculum of RKN only).
\end{abstract}

Results: Numerous high-quality reads were generated by Novogene, means of the RNA-seq method. After being aligned to the reference genome, four comparative transcriptomic profile maps between any pairwise comparisons were obtained to find significantly differentially expressed genes (DEGS) and three databases of induced resistance (IR)-related, nematode pathogenesis (NP)-related and basal resistance (BR)-related genes were gotten. By hierarchal clustering, the phylogenetic relationship between highly and fewer DGEs were obtained and classified the resistance and susceptible responses into two clusters after inoculation with RKN. Finally, the results were verified by RT-qPCR and analysis of important plant defense enzymes.

Conclusions: Within an integrated and more sustainable management approach, the use of biocontrol organisms, like $P$. chrysogenum, seems to be a promising alternative.

Keywords: Tomato, Meloidogyne incognita, Penicillium chrysogenum, induced resistance, transcriptome analvsis. RNA-sen

\section{Background}

2

*Correspondence: duanyx6407@163.com

1 Nematology Institute of Northern China, Shenyang Agricultural University,

No.120 Dongling Road, Shenyang 110866, China

Full list of author information is available at the end of the article
9 world. RKN is a very important disease of tomatoes

10 and causes severe reductions in yield and quality in

11 many parts of the world. It forces producers to seek

12 alternative strategies to control nematode because of

13 the restriction on the use of nematicides around the

14 world[5]. In terms of plant protection, to provide

15 resistance against pathogens by enhancing the

16 mechanisms of natural plant-defense is a potential

17 approach[6]. In addition to a broad spectrum of direct

18 and indirect approaches to protect crops from damage,

19 the concept of induced resistance (IR) by natural plant

20 activators will be a widely used method and replace 
nematicides as sustainable management methods[7, $\underline{8}]$. Within an integrated and more sustainable management strategy the use of biocontrol organisms, like Penicillium chrysogenum, seems to be a promising alternative. The biocontrol effect of $P$. chrysogenum against different pathogens has been observed in a wide range of plants and seems to involve both localized and systemic resistance in different forms and different mechanisms in three active forms mainly, like PAF, an antifungal protein from $P$. chrysogenum, which was a_cysteine-rich, cationic and low weight molecular[9], like Pen, an aqueous extract, which was from the dry mycelium of $P$. chrysogenum, a non-pathogenic ascomycete[10, $\underline{11}]$, and like the dry mycelium of $P$. chrysogenum (DMP), a waste product, which was from the pharmaceutical industry after inactivating by high temperature, which was generated by the residual product after producing penicillin[12]. To sum up, the possible action modes of $P$. chrysogenum may be distinguished into four categories just as Whipps described[13], as followed: (i) changing or improving the nutrition, morphology and development of the plant[12], (ii) competing directly or suppressing the pathogen[9], (iii) altering the biochemical related with mechanisms of defense response and IR in plant $[\underline{10}, \underline{11}, \underline{14}, \underline{15}]$, and (iv) evolution of an antagonistic microbiota in the rhizosphere[16, 17]. Additionally, its application in agriculture has been promoted to some extent in recent years[18].

Over recent years, the biocontrol effect against different pathogens in the presence of $P$. chrysogenum has been reported in a wide range of plants and pathogens, thus providing evidence for an indirect effect of $P$. chrysogenum on nematode infection through the modulation of host plant metabolism, but the data available concerning the application of $P$. chrysogenum to control nematode is little so far. Gotlieb et al. (2003) reported that DMP enhanced plant growth and caused a dose-dependent reduction in root galling index to protect tomato and cucumber plants against the RKN $M$. javanica in the field, besides, and the protection does not operate via IR[19]. In 2009, Siddiqui et al. demonstrated that $P$. chrysogenum used alone and in groups of two (Aspergillus niger, plant growth-promoting mycorrhizal fungi) could promote plant growth and reduce the reproduction of Meloidogyne incognita in tomato in the glasshouse for the first time[20]. So, the modes of action of $P$. chrysogenum -IR against nematodes remain unknown to a higher degree.

Resistance breeding is one of the most efficient strategy for managing root knot nematode currently, especially on Solanaceous plants[21]. So far, many genes related to RKN resistance have been identified in plants, such as $M i-1, M i-3, M i-7, M i-8, M i-9$, CaRKNR, Rk, CaSn, Me1, Me3, Me4, Me7, Mechl, Mech2, rkn1, GHWTR1, MIC3, Ma and CaMi[21-33]. Moreover, some of them have been applied to transgenic plants successfully. Besides, since the first RKN-resistance genes $M i-1$, which is from Solanum peruvianum, which encodes NB/LRR protein with a novel amino-terminal domain, and which is located on chromosome 7ALz[22], was identified and cloned in tomato, and since the first detailed transcription analysis of giant cells induced by RKN infecting was reported[34], more and more researchers have made an effort to explore new resistant genes, virulent genes, and mechanisms related to responses to plant-RKN infection by studying differentially expressed mRNA. Through the comparison between the transcriptome profiles of compatible and incompatible interactions between tomato plants and RKN, it was discovered that a gene encoding glycosyltransferase was regulated by nematode infection significantly, and was necessary for resistance to root knot nematode in the resistant (Mi-1) cultivars 'Motelle' [35]. At present, RKN resistance utilized for commercial tomato cultivars is conferred only by the $M i$ gene, which has a more restricted spectrum and a reduced efficiency at high temperature. For controlling the disease, novel methods were needed to develop. Therefore, it is demanded to better understand the interaction molecular modes between plant and the pathogen in tomato. To achieve the goal, it is essential to discover the variation of gene expression in infected tomato. In turn, it will contribute to the employment of genes which are both crucial in susceptible and resistant responses to RKN. In addition, it may be an alternative mean to the development of cultivars which are with persistent resistance that to take advantage of multiple resistant genes or to knock down (out) crucial 
susceptible genes in resistance breeding. Due to different genetic backgrounds of incompatible and compatible host plants, cross-comparisons among different treatments of resistant and susceptible plants cannot be achieved, like the commonly or differently expressed genes between the resistant plants with no inoculation and susceptible plant after inoculation.

Although some investigations on resistance-related genes of resistant lines or pathogenicity-related genes of susceptible lines have been performed respectively, there has not been a systematic study on the mechanism of induced resistance to RKN and the pathogenic mechanism of RKN in the same line, moreover reflecting the natural immune mechanism of plant to a certain extent at the same time. The development of natural genes means a new disease-resistant breeding pathway, which reduces the difficulty to some extent; means no instability and no potential danger of transgenes to some extent; means avoiding the embarrassing situation that the fruit taste and plant resistance are opposite to some extent. Previously, P. chrysogenum Snef1216 was screened by seed-coating which showed a high activity of IR to RKN in tomato, and the control effect was verified by splitting the root in our earlier researches[36]. The histopathological study indicated that the giant cell in tomato roots treated by Snef1216 fermentation broth with a slow metabolism cannot provide sufficient nutrition for the further development of nematodes. So, the treatment could reduce the second-stage juveniles (J2) number of initial infecting as well as restrain the development of nematode[37]. These findings indicate that Snef1216 could be a promising biocontrol agent. However, no information is available regarding the molecular mechanism of Snef1216 inducing resistance to RKN.

In the present study, next-generation high-throughput RNA-seq was used to monitor and compare DEGs in tomato inoculated with RKN or not with those in a control group, and our objectives were (i) to investigate and compare, using comparative transcriptome analysis, the global gene expression changes in Snef1216 fermentation broth seed-coating tomato roots with those in a control group inoculated with and without RKN, (ii) to identify and validate the potential genes which involved in Snef1216 induced
159 RKN resistance and which involved in susceptible 160 responses, (iii) to perform biochemical analysis of the 161 enzymes involved in the disease response pathways 162 during compatible and incompatible interactions, (iv) 163 to know about possible plant natural immune 164 mechanism. The results revealed a large number of 165 DEGs of Snef1216-induced tomato roots infected by 166 RKN with control groups, and have the potential to 167 assist in the development of new disease control 168 strategies and resistance breeding. All the knowledge 169 on the underlying mechanisms of $P$. chrysogenum 170 Snef1216-IR against plant-parasitic nematodes could 171 lead to the improvement of the use of $P$. chrysogenum 172 as biocontrol organisms.

\section{Methods}

\section{Biological Materials}

175 Plant Materials and Growth Conditions

176 Tomato seeds (Solanum lycopersicum L. cv. L-402, 177 which is a susceptible tomato cultivar to M. incognita 178 [38], and which was purchased from Liaoning 179 Horticultural Seedling Co., Ltd.) were sterilized with 180 ethanol $(75 \% \mathrm{v} / \mathrm{v})$ for $1 \mathrm{~min}$, and then disinfected with 181 sodium hypochlorite $(2.5 \% \mathrm{v} / \mathrm{v})$ for $1 \mathrm{~min}$. To wash 182 seeds with sterile water for 5 times was followed after 183 each sterilization step. Subsequently, to coat dry seeds 184 with $P$. chrysogenum Snef1216 fermentation broth 185 (control seeds were sterilized similarly, but coated with 186 sterile water) in a volume ratio of 1:4 (Snef1216: seeds) 187 and to air-dry in a dry and ventilated place. Tomato 188 plants were grown in $1 \mathrm{~L}$ pots which were filled with 189 substrate mixture in a volume ratio of 1:1:1 (sand: 190 loam: potting soil) and kept in the greenhouse 191 conditions with $75 \%$ relative humidity and $20-27^{\circ} \mathrm{C}$ 192 day/night. After four true leaves were fully expanded, 193 RKN were inoculated to the roots of L-402 seedlings.

\section{Nematode Inoculum}

195 The inoculum of RKN, M. incognita, originally 196 isolated from naturally infected tomato for the 197 experiments was obtained by pure culture raised from 198 a single egg mass and maintained on the roots of $M$. 199 incognita susceptible tomato cultivar L-402 under 200 greenhouse conditions. The total root system of the 201 infected plants was immersed in water and removed 
adhering soil by gentle washing after being uprooted from soil. Second-stage juveniles (J2) of M. incognita were obtained from egg masses which were hand-picked from roots infected with RKN in tomato cv. L-402. For dissolving the gelatinous matrix, egg masses were placed in sodium hypochlorite $(0.5 \% \mathrm{v} / \mathrm{v})$ after rinsing with sterile water and agitating for $4 \mathrm{~min}$, followed by washing with sterile water on a sieve which was with $26 \mathrm{~mm}$ pores. According to the modified Baermann funnel method, freshly hatched J2 were obtained and in use for three days. After being watered to field capacity, per plant were inoculated with 2000/5ml (J2/water) in five holes which were $1 \mathrm{~cm}$ deep and around the stem base in the potting substrate. In the control experiment, $5 \mathrm{ml}$ of sterile water substituted the nematode suspension with similar treatment. The experiment was made up of four treatment, and organized in a design which were randomized completely, namely negative control 'CKCK' (no inoculum), pathogen control ' $\mathrm{CKN}$ ' (inoculum of $M$. incognita only), inducer control 'IRCK' (induced by $P$. chrysogenum only) and pathogen + inducer 'IRN' (induced by P. chrysogenum and inoculum of $M$. incognita). 15 days after inoculation (dpi), five plants in each group were selected randomly, followed by root collection and gentle washing for removing attached substrate. RNAs were extracted from the roots of each group after being combined, immediately frozen and stored at $-80^{\circ} \mathrm{C}$, and the samples were labeled.

\section{RNA Extraction, Library Construction, and RNA-Seq}

RNA extraction, library construction and RNA-seq were operated following the method of Liu et al. with modifications[39]. RNA degradation and contamination were monitored on $1 \%$ agarose gels. RNA purity was checked by using the Nano Photometer spectrophotometer (IMPLEN, CA, USA). RNA concentration was measured by using Qubit RNA Assay Kit in Qubit 2.0 Fluorometer (Life Technologies, CA, USA). RNA integrity was assessed by using the RNA Nano 6000 Assay Kit of the Bioanalyzer 2100 system (Agilent Technologies, CA, USA). A total amount of $3 \mu \mathrm{g}$ RNA per sample was used as input material for the RNA sample preparations. Sequencing
247 libraries were generated using NEBNext Ultra RNA 248 Library Prep Kit for Illumina (NEB, USA) following 249 the manufacturer's recommendations and index codes 250 were added to attribute sequences to each sample. 251 Briefly, mRNA was purified from total RNA by using 252 poly-T oligo-attached magnetic beads. Fragmentation 253 was carried out by using divalent cations under 254 elevated temperature in NEBNext First-Strand 255 Synthesis Reaction Buffer (5X). First strand cDNA 256 was synthesized by using random hexamer primer and 257 M-MuLV Reverse Transcriptase (RNase H). 258 Second-strand cDNA synthesis was subsequently 259 performed by using DNA Polymerase I and RNase H. 260 Remaining overhangs were converted into blunt ends 261 via exonuclease/ polymerase activities. After 262 adenylation of 3' ends of DNA fragments, NEB Next 263 Adaptor with hairpin loop structure were ligated to 264 prepare for hybridization. In order to select cDNA 265 fragments of preferentially 150 200 bp in length, the 266 library fragments were purified with AMPure XP 267 system (Beckman Coulter, Beverly, USA). Then $3 \mu 1$ 268 USER Enzyme (NEB, USA) was used with 269 size-selected, adaptor-ligated cDNA at $37^{\circ} \mathrm{C}$ for $15 \mathrm{~min}$ 270 followed by $5 \mathrm{~min}$ at $95^{\circ} \mathrm{C}$ before PCR. Then PCR was 271 performed with Phusion High-Fidelity DNA 272 polymerase, Universal PCR primers and Index (X) 273 Primer. At last, PCR products were purified (AMPure 274 XP system) and library quality was assessed on the 275 Agilent Bioanalyzer 2100 system.

\section{Sequence Data and Differentially}

277 Expressed Gene Analysis

278 The data of sequence and the expression of differential 279 genes were analyzed by using the method described by 280 Liu et al. with modifications[39]. Raw data (raw reads) 281 of fastq format were firstly processed through in-house 282 perl scripts. In this step, clean data (clean reads) were 283 obtained by removing reads containing adapter, reads 284 containing ploy- $\mathrm{N}$ and low-quality reads from raw data. 285 At the same time, Q20, Q30 and GC content clean data 286 were calculated. All the downstream analyses were 287 based on the clean data with high quality. The Solanum 288 lycopersicum reference genome 289 (ftp://ftp.ensemblgenomes.org/pub/release-23/plants/fa 290 sta/solanum_lycopersicum/dna/) and gene model 291 annotation files 
292 (ftp://ftp.ensemblgenomes.org/pub/release-23/plants/gt

293 f/solanum_lycopersicum/) were downloaded from the

294 genome website directly. Index of the reference 295 genome was built by using Bowtie v2.2.3 and 296 paired-end clean reads were aligned to the reference 297 genome by using TopHat v2.0.12, and generated a 298 database of splice junctions based on the gene model 299 annotation file. HTSeq v0.6.1 was used to count the 300 reads numbers mapped to each gene. And then FPKM 301 of each gene was calculated based on the length of the 302 gene and reads count mapped to this gene. Differential 303 expression analysis of two groups was performed by 304 using the DESeq R package (1.18.0). DESeq provided 305 statistical routines for determining differential 306 expression in digital gene expression data by using a 307 model based on the negative binomial distribution. The 308 resulting $P$-values were adjusted by using the 309 Benjamini and Hochberg's approach for controlling the 310 false discovery rate. Genes with an adjusted $P$-value $311<0.05$ found by DESeq were assigned as differentially 312 expressed.

\section{Functional Analysis of Differentially 314 Expressed Genes}

315 The functional analysis of DEGs were carried out by 316 applying the method of Liu et al with 317 modifications[39]. Gene Ontology (GO) enrichment 318 analysis of differentially expressed genes was 319 implemented by the GOseq R package, in which gene 320 length bias was corrected. GO terms with corrected $321 P$-value less than 0.05 were considered significantly 322 enriched by differentially expressed genes[40], which 323 was categorized in biological processes, cellular 324 component, and molecular functions. Differentially 325 expressed genes were also subjected to KOBAS 326 analysis by using KOBAS software[41-43] to test the 327 statistical enrichment of differential expression genes 328 in Kyoto Encyclopedia of Genes (KEGG) pathways 329 (http://www.genome.jp/kegg/). Protein-Protein 330 Interaction (PPI) analysis of differentially expressed 331 genes was based on the STRING database, which was 332 knew and predicted protein-protein interactions. For 333 the species existing in the database, the networks were 334 constructed by extracting the target gene list from the 335 database. Additionally, Blastx (v2.2.28) was used to 336 align the target gene sequences to the selected
337 reference protein sequences, and then the networks 338 were built according to the known interaction of 339 selected reference species. The Cufflinks v2.1.1 340 Reference Annotation Based Transcript (RABT) 341 assembly method was used to construct and identify 342 both known and novel transcripts from TopHat 343 alignment results. Alternative splicing events were 344 classified to 12 basic types by the software Asprofile 345 v1.0. The number of AS events in each sample was 346 separately estimated. Picard-tools v1.96 and samtools 347 v0.1.18 were used to sort, mark duplicated reads and 348 record the bam alignment results of each sample. 349 GATK2 (v3.2) software was used to perform SNP 350 calling.

\section{Quantitative Real-Time PCR (RT-qPCR) 352 Validation of RNA-Seq Data}

353 According to the protocol of manufacturer, the 354 Ultrapure RNA Kit (CWBIO) was used to extract the 355 total RNA of the collected samples. Then the cDNA of 356 the first-strand was synthesized by applying the 357 PrimeScript RT reagent Kit with gDNA Eraser (Perfect 358 Real Time) (Takara) in accordance with the 359 instructions of manufacturer, followed by measuring 360 the concentration of cDNA by the NanoVue Plus 361 instrument (BIOCHROM LTD CAMBRIDGE, 362 ENGLAND). Primers of tomato actin genes as the 363 control and 20 interested genes which may play a role 364 of plant defense for RT-qPCR as listed in Table S1, 365 were designed by using the Primer Premier 5.0 366 software. TB Green Premix Ex Taq II (Tli RNaseH 367 Plus) (Takara) was used to perform the RT-qPCR 368 reactions on a CFX96 Real-Time PCR Detection 369 System (BIO-RAD) platform. The amplification was 370 made up of one cycle of $95^{\circ} \mathrm{C}$ for $30 \mathrm{~s}$, followed by the 371 denaturation which consisted of 40 cycles of $95^{\circ} \mathrm{C}$ for $37230 \mathrm{~s}$, annealing and extension at $60^{\circ} \mathrm{C}$ for $30 \mathrm{~s}$. At the 373 last step of each cycle, fluorescent products were 374 detected. For ensuring the proper of amplification of 375 target fragments, a melting curve was examined after 376 all cycles. Subsequently, the $2^{-\Delta \Delta \mathrm{CT}}$ method was used

377 to normalize and calibrate the relative expression 378 levels[44]. Three technical replicates and three 379 biological replicates were performed of all reactions of 380 interested genes. 
a

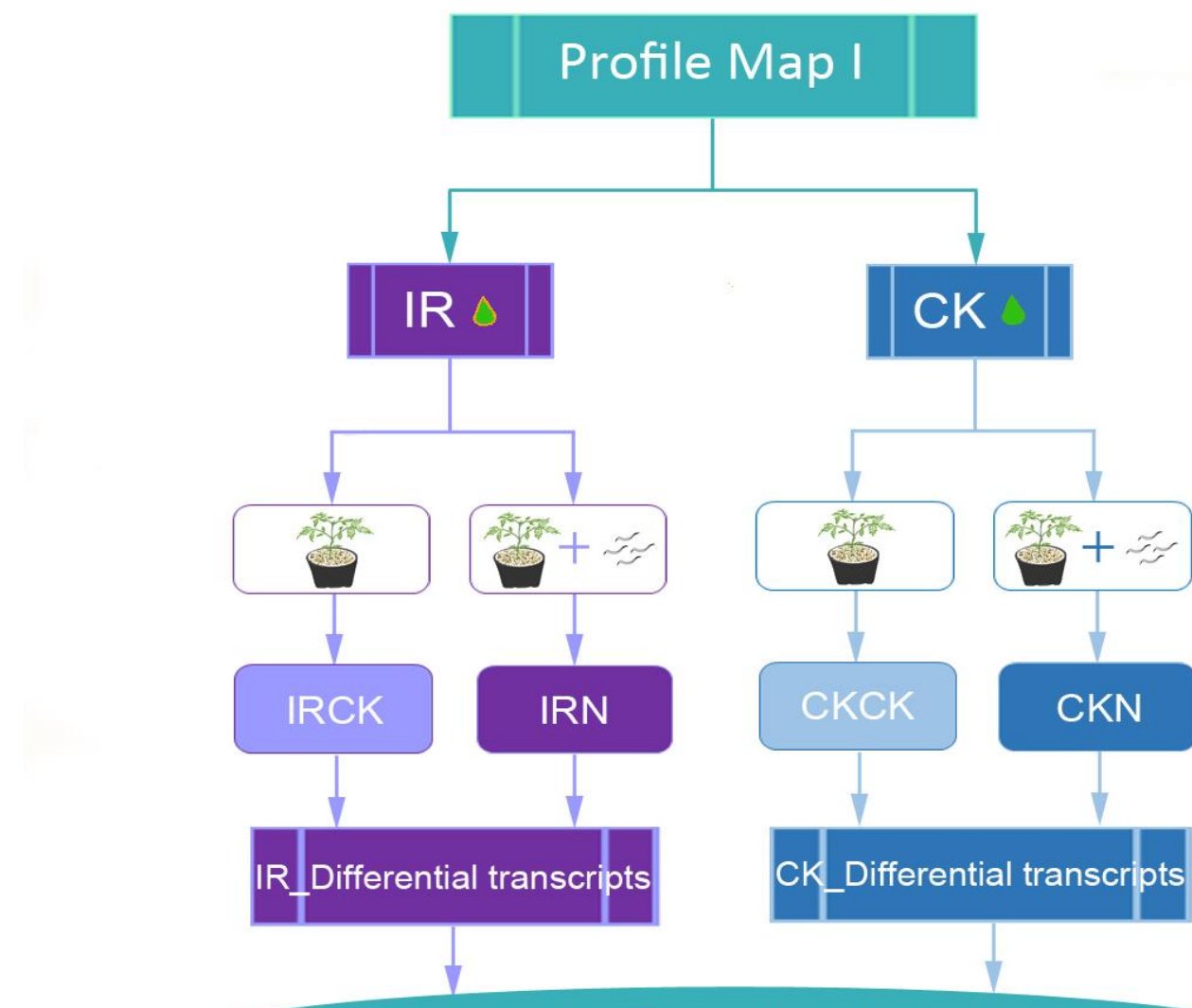

Comparative Transcriptomic Analysis

b
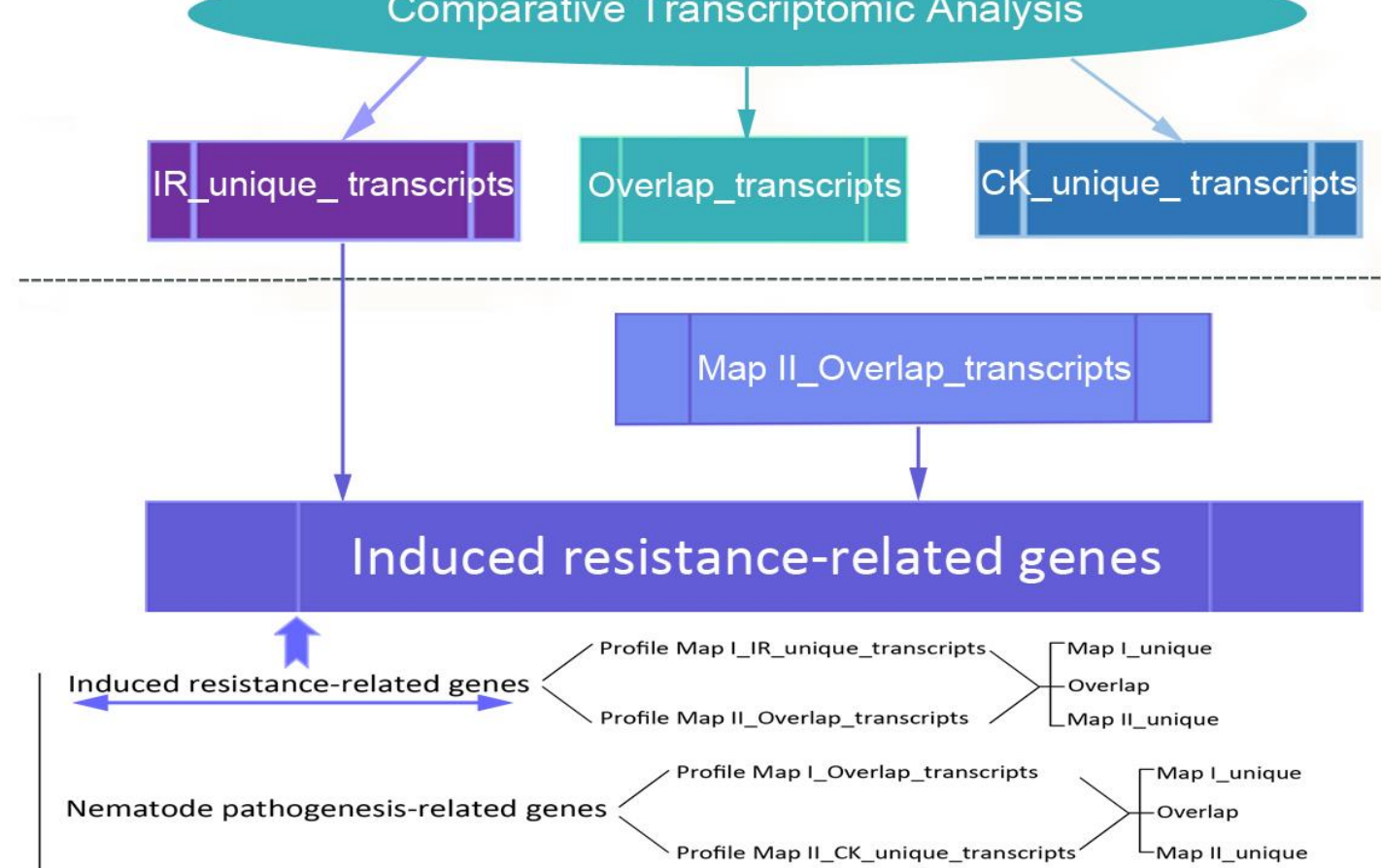

Basal resistance-related genes $\overbrace{\text { Profile Map IV_Overlap_transcripts }}^{\text {Profile Map III_Overlap_transcripts }}>\left[\begin{array}{l}\text { Map III_unique } \\ \text { Overlap } \\ \text { Map IV_unique }\end{array}\right.$

Fig. 1 a. One of the profile maps for comparative transcriptomic analysis, namely profile map I- (IRN vs IRCK) vs (CKN vs CKCK). Firstly, constructed mRNA-seq libraries of different treatments; Secondly, generated transcriptome data of each mRNA library; Thirdly, obtained differential transcripts of induced resistant (IR) group and control (CK) group, respectively; Finally, comparatively analyzed between the IR and CK groups, and obtained their own and shared transcripts. The remaining few were profile map II(IRCK vs CKCK) vs (IRN vs CKN), profile map III- (IRCK vs CKCK) vs (CKN vs CKCK), profile map IV- (IRCK vs CKCK) vs (IRN vs IRCK), respectively. b. Graphic presentation of the mapping design of results analysis. 


\section{Assay of Defense Enzyme Activities}

383 The methods of seed treatment, nematode inoculation

384 and sampling in tomato were as described above, and 385 the sampling times were selected at two-leaf stage, 386 pre-transplant, $0,5,10,15,20,25$, and $30 \mathrm{dpi}$, 387 respectively. phenylalanine ammonia lyase (PAL) 388 activity was estimated with L-phenylalanine as the 389 substrate by using the method of Chen et al. with 390 modifications[45]. PAL specific activity was monitored 391 at $290 \mathrm{~nm}$. Peroxidase[4] activity was determined 392 following the oxidation of guaiacol in the presence of 393 hydrogen peroxide following the method described by 394 Yan et al. with modifications[46]. POD activity was 395 expressed as protein changes in absorbance at $470 \mathrm{~nm}$. 396 Polyphenol oxidase (PPO) activity was examined 397 spectrophotometrically following the oxidation of 398 catechol by applying the method of Mohammadi and 399 Kazemi with modifications[47]. The absorbance was $400 \mathrm{read}$ at $398 \mathrm{~nm}$ against the blank solution, which 401 included the same volume of reaction mixture but 402 replacing the enzyme extract with buffer. One unit of 403 enzyme activity was defined as the change in the OD 404 value of 0.1 , and the activity is expressed in $\mathrm{U} / \mathrm{g}$. 405 Calculation formula:

406 The enzyme activity $(\mathrm{U} / \mathrm{g})=\frac{\Delta O D \cdot V_{R} \bullet V_{G}}{0.1 \cdot A \bullet T \bullet G}$

$407 \Delta \mathrm{OD}$ : change in absorbance before and after reaction

$408 \mathrm{~V}_{\mathrm{R}}$ : total volume of the reaction system

$409 \mathrm{~V}_{\mathrm{G}}$ : total volume of enzyme crude extract

410 A: dosage of enzyme solution used in the measurement

411 T: reaction time $(\mathrm{min})$

412 G: fresh weight of root $(\mathrm{g})$

\section{Results}

414 In order to observe the influence of the P. chrysogenum

415 Snef1216-induced expression level of the genes 416 involved in resistance against the $M$. incognita in 417 L-402 tomato, four cDNA samples of the IR, namely 418 IRCK and IRN as well as CK, namely CKCK and $419 \mathrm{CKN}$ were extracted at $15 \mathrm{dpi}$, then 4 comparative 420 transcriptomic profile maps between different pairwise 421 comparisons were obtained (Fig.1a). Subsequently, 422 three databases of IR-related genes (resistance), 423 NP-related genes (pathogenicity) and BR-related 424 genens were gotten by analyzing the result, 425 respectively.

426 Basal resistance is a defense response which is 427 unsuccessful eventually to infection with a virulent 428 pathogen in plant, which is believed to be triggered by 429 recogniting the pathogen-associated molecular patterns 430 in host, with inhibition of particular components by 431 pathogen effectors subsequently[48]. The graphic 432 presentation of the analysis roadmap was shown in 433 Fig.1b.

\section{Sequence Analyzing and Aligning to the 435 Reference Genome}

436 After constructing the mRNA-seq libraries of different 437 treatments, sequencing was completed by Illumina 438 mRNA-Seq technology. For further analysis, 439 high-quality reads of approximately 460-560 million 440 (M) reads with 95\% Q30 bases (those with a base 441 quality greater than 30) were selected following 442 stringent quality assessment and data cleaning. An 443 average ' $\mathrm{G}+\mathrm{C}$ ' content of above $40 \%$ was found. Of 444 the selected reads, $87.63,89.89,90.24,89.94 \%$ from 445 the IRN, CKN, IRCK and CKCK samples were

\begin{tabular}{|c|c|c|c|c|c|c|c|c|}
\hline \multirow{2}{*}{$\begin{array}{l}\text { Statistical } \\
\text { content }\end{array}$} & \multicolumn{2}{|c|}{ IRN } & \multicolumn{2}{|c|}{ CKN } & \multicolumn{2}{|r|}{ IRCK } & \multicolumn{2}{|c|}{ CKCK } \\
\hline & Number & Percentage & Number & Percentage & Number & Percentage & Number & Percentage \\
\hline Total reads & 49703467 & $100 \%$ & 55484460 & $100.00 \%$ & 46017771 & $100.00 \%$ & 47091116 & $100.00 \%$ \\
\hline Total mapped & 43693519 & $87.63 \%$ & 49866552 & $89.89 \%$ & 41531857 & $90.24 \%$ & 42349546 & $89.94 \%$ \\
\hline Multiple mapped & 256227 & $0.51 \%$ & 338631 & $0.60 \%$ & 236570 & $0.52 \%$ & 263266 & $0.56 \%$ \\
\hline Uniquely mapped & 43437292 & $87.12 \%$ & 49527921 & $89.30 \%$ & 41295287 & $89.73 \%$ & 42086280 & $89.38 \%$ \\
\hline Reads map to ' +' & 21717016 & $43.55 \%$ & 24752173 & $44.63 \%$ & 20625771 & $44.81 \%$ & 21021399 & $44.65 \%$ \\
\hline Reads map to ' -' & 21720276 & $43.56 \%$ & 24775748 & $44.67 \%$ & 20669516 & $44.91 \%$ & 21064880 & $44.74 \%$ \\
\hline Non-splice reads & 29207866 & $58.59 \%$ & 32167624 & $58.34 \%$ & 25212817 & $54.76 \%$ & 25859408 & $54.92 \%$ \\
\hline Splice reads & 14229426 & $28.52 \%$ & 17360297 & $30.96 \%$ & 16082470 & $34.97 \%$ & 16226872 & $34.46 \%$ \\
\hline
\end{tabular}


aligned onto the tomato reference genome and matched either unique or multiple genomic locations (Table1).

\section{Analysis of Differentially Expressed 449 Genes}

450 To study the DEGs between different pairwise 451 comparisons, genes of twofold up-regulated and 452 twofold down-regulated employing adjusted $P$-value $453<0.05$ found by DESeq were identified. In the case of 454 IR-related group, a total of 1504 DEGs were identified, 455 of which 419 were up-regulated, whereas 1085 genes 456 were found to be down-regulated. Correspondingly, a 457 total of 534 genes were found to be differentially 458 expressed in NP-related group. Of these, the up- and 459 down-regulated respectively were 87 and 447. In total, 460 in the case of BR-related group, 732 DEGs were 461 identified, of which 236 were up-regulated and 496 462 were down-regulated. Moreover, the database of the 463 induced resistance-related group which were obtained 464 from two parts of Map I_IR_unique transcripts and 465 Map II _overlap transcripts, and the nematode 466 pathogenesis-related database which come from two 467 parts of Map II_CK _unique transcripts and Map I 468 _overlap transcripts were all independent and did not

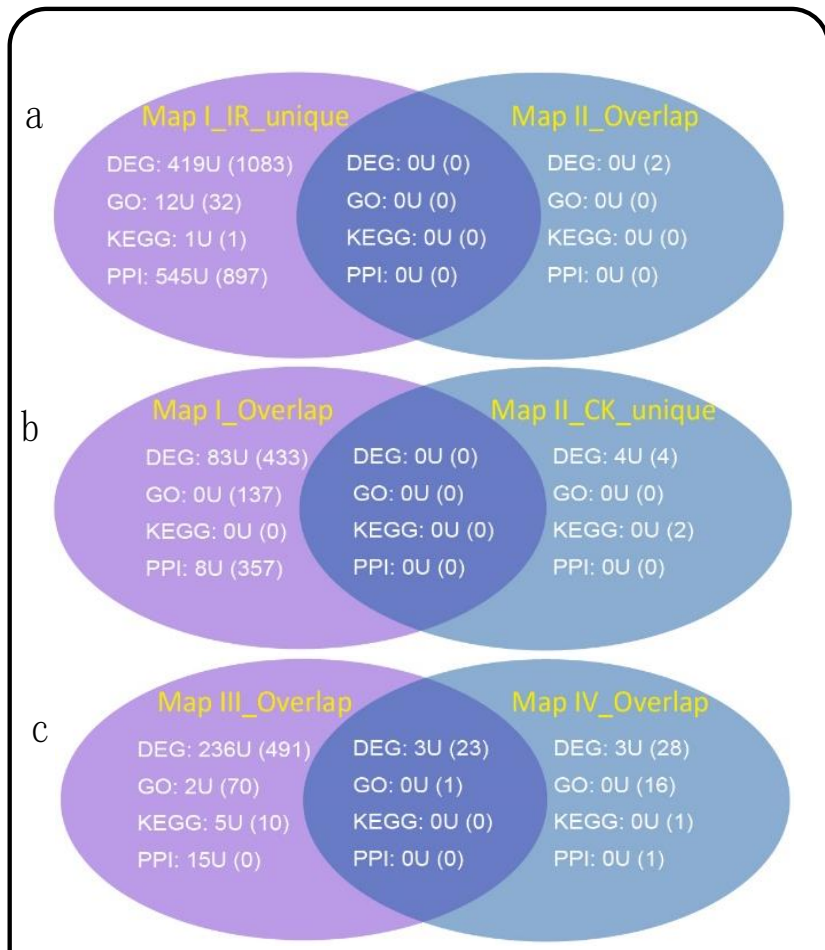

Fig. 2 Venn diagrams of differential transcripts in (a) induced resistance-related, (b) nematode pathogenesis-related and (c) basal resistance-related groups following M. incognita inoculation at 15day post inoculation (dpi). Numbers in parentheses indicate down-regulated
469 intersect each other, respectively. In IR-related 470 database, only two down-regulated genes were from 471 Map II _overlap transcripts, the rest all came from 472 Map I_IR _unique transcripts, of which 419 were 473 up-regulated and 1083 were down-regulated. In the 474 case of NP-related database, 4 up-regulated and 14 475 down-regulated were from Map II_CK _unique 476 transcripts. All the rest came from Map I _overlap 477 transcripts. Of these, up- and down-regulated were 83 478 and 433, respectively. However, the situation was 479 different in the last database, which was derived from 480 the two parts of Map III_overlap transcripts and Map 481 IV _overlap transcripts. Of it, 236 genes were uniquely 482 up-regulated and 491 genes exclusively downregulated 483 in Map III _overlap transcripts. Similarly, in the Map 484 IV _overlap transcripts, unique up- and 485 down-regulated genes were 3 and 28, respectively. In 486 addition, 3 up-regulated and 23 down-regulated genes 487 were shared between the two parts in all. (Fig.2, 488 Supplementary Table S1,2,3)

489 Functional Annotation and Classification 490 of Different Expression Analysis

491 It was considered that differentially expressed genes 492 (DEGs) were the significant cause of either induced 493 defense response or pathogenic response of nematode, 494 or basal resistance response. To better investigate the 495 biological behavior of these responses, it is necessary 496 to understand the functional distribution of these DEGs. 497 Thus, GO, KEGG, and PPI analyses of the main 498 functional groups of the DEGs were implemented and 499 generated respective databases. In IR-related group, 500 the whole differential expression was from Map I_IR 501 _unique. Overall, 51, 2, 1442 different GO terms, 502 KEGG pathways and PPI respectively were subjected, 503 of which 12, 1, 545 were up-regulated, while 32, 1, 504897 were found to be down-regulated. In the case of 505 NP-related groups, the differential up- and 506 down-regulated genes of the above three terms were 0 , 507 0, 8 and 137, 2, 357, respectively. Among them, only 508 two down-regulated KEGG pathways were from Map 509 II_CK_unique transcripts, the rest 0, 0, 8 up-regulated 510 and 137, 0, 357 down-regulated of the above three 511 terms were all from Map I _overlap transcripts. In the 512 BR-related group, 96, 18, 16 of the above three terms 513 were found to be differential. Of these, the up- and 
a.

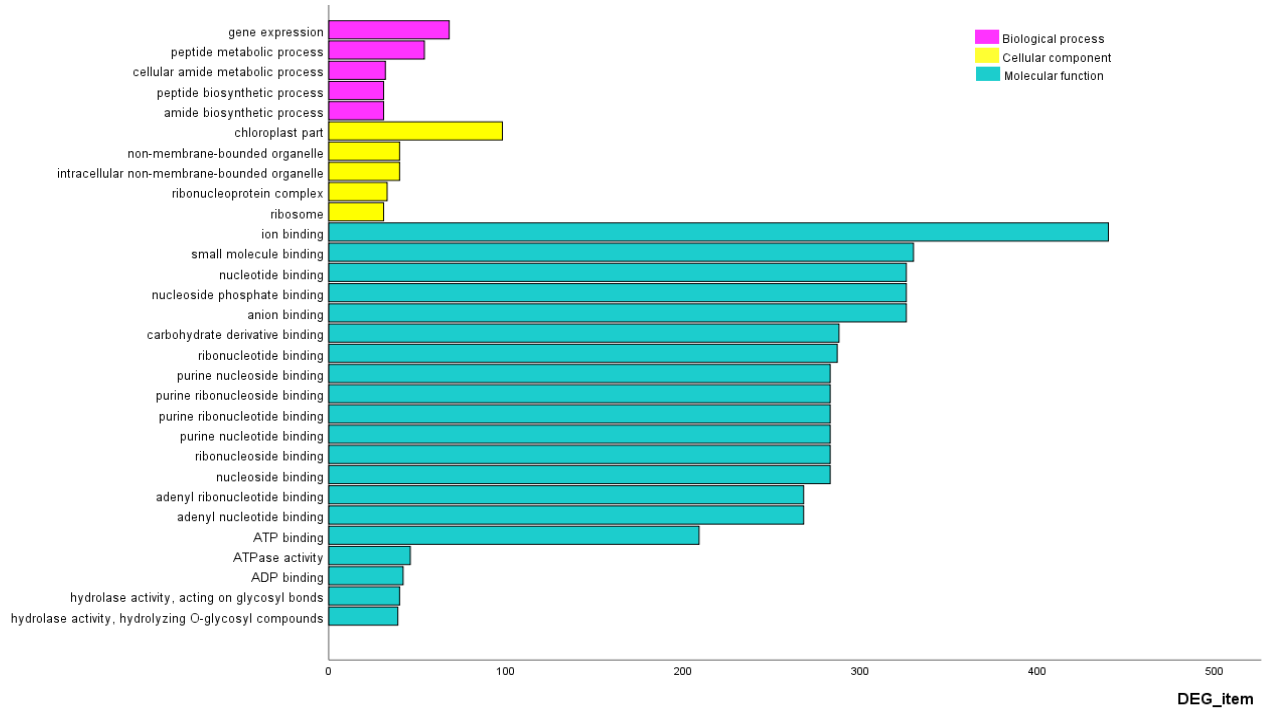

b.

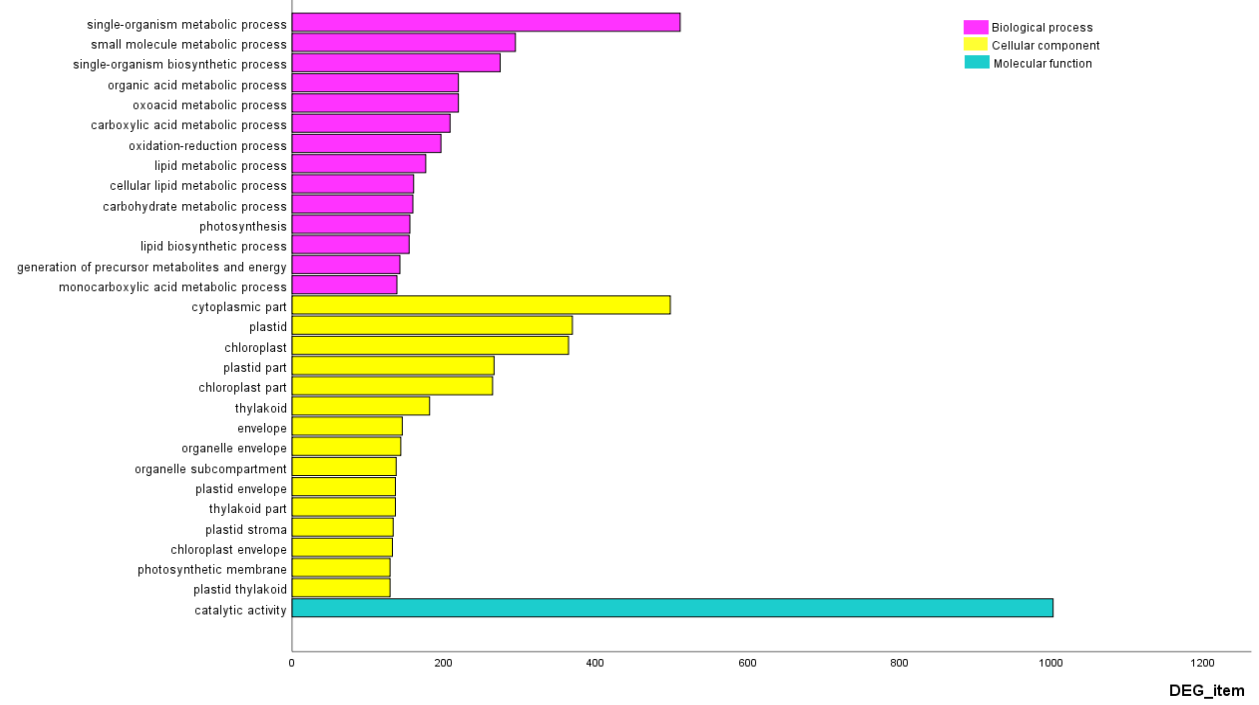

c.

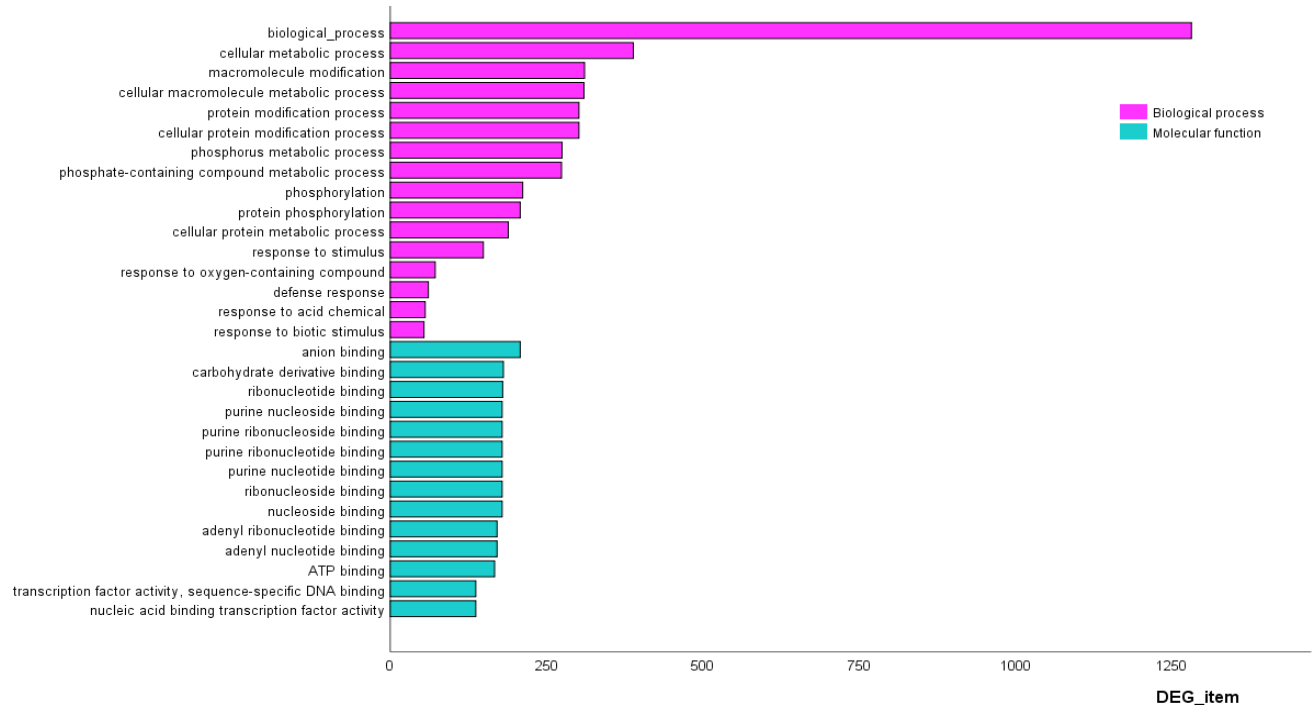

Fig. 3 G0 annotations of differentially expressed genes (a) G0 annotation related to induced resistance, (b) G0 annotation related to nematode pathogenesis and (c) G0 annotation related to 
514 down-regulated respectively were $2,5,15$ and 85,10 ,

5151 of every term. Additionally, different from the first

516 two groups that had no co-expression, the last database 517 consisted of three parts, some of which were uniquely 518 expressed in Map III _overlap transcripts (2, 5, 15 519 up-regulated and 70, 10, 0 down-regulated), another 520 part was exclusively expressed in the Map IV _overlap 521 transcripts (16, 1, 1 down-regulated). Furthermore, one 522 down-regulated GO term (GO:0010200: response to 523 chitin) was shared between the two parts. (Fig. 2)

\section{Genes Annotation-Related with Induced 525 Resistance}

526 It grouped genes associated with induced resistance 527 specifically in accordance with their involved 528 pathways. According to Gene Ontology (GO), a gene 529 functional classification system which is standardized 530 internationally, GO terms with corrected $P$-value less 531 than 0.05 , which were knows as significant enrichment 532 by differentially expressed genes, were classified into 533 three major functional ontologies. For the unique 534 annotations of IR-related group, 'gene expression' (68) 535 and 'peptide metabolic process' (54) were the main 536 dominant subcategories, followed 'cellular amide 537 metabolic process' (32), 'peptide biosynthetic process' 538 (31), 'amide biosynthetic process' (31) and 539 'translation' (30) in the category of biological process 540 (BP). For molecular function (MF), 'ion binding' (440), 541 'small molecule binding' (330), 'anion binding' (326), 542 'nucleotide binding' (326) and 'nucleoside phosphate 543 binding' (326) were highly represented. Among 544 cellular component (CC) terms, which were almost 545 up-regulated, dominant subcategories were 546 'chloroplast part' (98), 'intracellular 547 non-membrane-bounded organelle' (40) and 548 'non-membrane-bounded organelle' (40). Different 549 from the GO terms, there was only one up-regulated 550 (Ribosome) and one down-regulated (Photosynthesis 551 -antenna proteins) differentially expressed KEGG 552 pathways in this group. (Fig.2,3)

\section{Genes Annotation-Related with Nematode 554 Pathogenesis}

555 The annotations exclusively belonging to NP-related 556 group were different. In the BP category, the most 557 represented was 'single-organism metabolic process' 558 (511), following 'small molecule metabolic process'
559 (294) and 'single-organism biosynthetic process' (274). 560 For MF, 'catalytic activity' (1002) were highly 561 represented. In the category of $\mathrm{CC}$, dominant 562 subcategories were 'cytoplasmic part' (498), 'plastid' 563 (369) and 'chloroplast' (364). Furthermore, in this 564 group, only two down-regulated KEGG pathways 565 'Linoleic acid metabolism' and 'alpha-Linolenic acid 566 metabolism' were differentially expressed. (Fig.2,3)

\section{Genes Annotation-Related with Basal 568 Resistance}

569 For the exclusive annotations of BR-related group, the 570 most DEGs were localized to 'biological_process' 571 (1282) in the BP category. A few DEGs were localized 572 to 'cellular metabolic process' (389). Among MF terms, 573 a large number of DEGs were involved in 'anion 574 binding' (208). In addition, a few DEGs belonged to 575 two functional subclasses, 'carbohydrate derivative 576 binding' (181) and 'ribonucleotide binding' (180). In 577 the CC category, there was only one GO term, which 578 was 'photosystem II' (14). Based on the results of 579 KEGG annotation, most DEGs were localized to 580 'Metabolic pathways' (1961) and 'Biosynthesis of 581 secondary metabolites' (1036). In addition, a few 582 DEGs belonged to two functional subclasses, 'Plant 583 hormone signal transduction' (301), 'Carbon 584 metabolism' (253), 'Phenylpropanoid biosynthesis' 585 (190), 'Phenylalanine metabolism' (152) and 586 'Glycolysis / Gluconeogenesis' (122). (Fig.2,3)

\section{Hierarchical clustering}

588 The hierarchical clustering analysis classified the 589 resistant and susceptible responses into two clusters 590 after inoculation with $M$. incognita. By hierarchal 591 clustering, obtained the phylogenetic relationship 592 between highly and less differentially expressed genes. 593 The expression changes among the gene group 594 members in eight clusters: (i) defense-associated 595 response, (ii) signal transduction, (iii) cell death, (iv) 596 transcription factor, (v) oxidoreductases, (vi) defense 597 enzymes activity, (vii) protease inhibitor, (viii) 598 phenylpropanoid metabolism, were represented by 599 different colors in the heat map. The color intensities 600 indicate the expression level of each gene. (Fig.4; 601 Supplementary Table S4) 


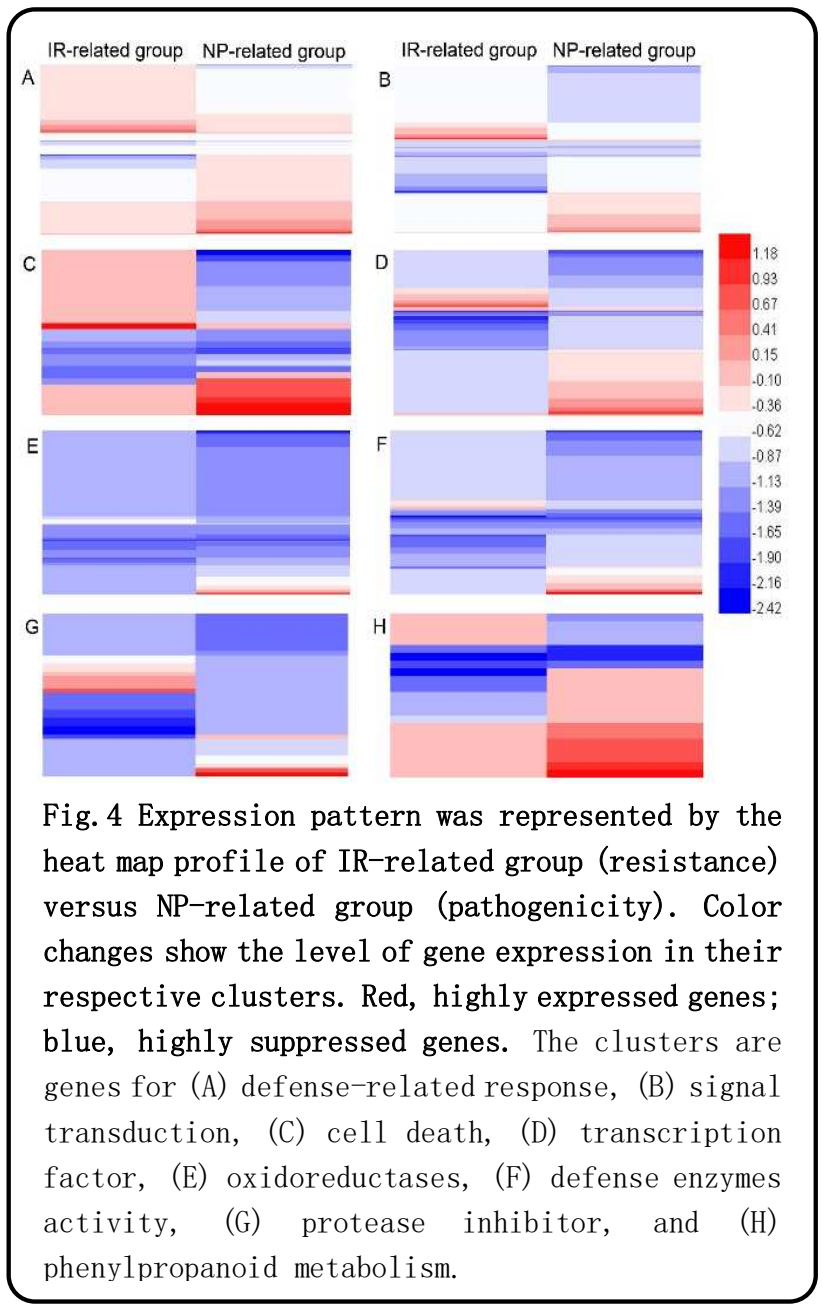

602 Validation of Differentially Expressed 603 Genes by RT-qPCR

60412 DEGs with a putative role in plant defense, which

605 belong to the categories of defense, signal transduction,

606 cell death, transcription factor, oxidoreductases,

607 defense enzymes activity, protease inhibitor or

608 phenylpropanoid metabolism, were selected and

609 examined with specific primers by RT-qPCR to

610 validate the reliability of the RNA-Seq data

611 (Supplementary Table S1). Gene expressions in control

612 plants (CKCK), Snef1216-coated plants (IRCK),

613 nematode-infected plants[1] and Snef1216

614 nematode-infected plants (IRN) were compared. Then

615 the relative expression of genes in the control group

616 (CKN vs CKCK) and the treatment group (IRN vs

617 IRCK) were obtained. Genes encoding myb-related

618 protein 315-like, peroxidase P7-like, putative disease

619 resistance protein RGA4 showed high up-regulation

620 only in Snef1216-induced nematode-infected roots

621 [49]. Genes encoding disease resistance protein

622 RPP13-like, auxin-responsive protein IAA. $15.4 \mathrm{kDa}$
623 class $\mathrm{V}$ heat shock protein, apoptosis-inducing factor

624 homolog A-like, extra-large guanine

625 nucleotide-binding protein 1-like were higher

626 up-regulated in the treatment group than in control

627 group (Fig.5defgh). The relative expressions of genes

628 encoding protein BREAST CANCER

629 SUSCEPTIBILITY 1 homolog, peroxidase 3, probable

630 glycosyltransferase At3g07620 and transcription factor

631 MYB48 were lower in treatment group than in control

632 group (Fig.5ijkl). According to the expression patterns

633 of RT-qPCR_at 15dpi, the results of the DEGs which

634 were selected randomly were consistent with the

635 RNA-seq data in each of three biological replicates,

636 demonstrating that the expression patterns which were

637 obtained by RNA-seq reflected the real gene expressed

638 patterns in the compatible interaction and induced

639 resistance interaction in tomato.

640 Biochemical assay of enzymes involved in 641 defense response

642 Besides transcription level, the possible roles of 643 induction and inoculation at the translational level 644 were also examined. Thus, the activities of different 645 important defense enzymes were measured in CKCK, 646 CKN, IRCK and IRN plants at two-leaf period, 647 pre-transplanting period (four-leaf period), 0, 5, 10, 15, 648 20, 25 and 30dpi individually, and compared between 649 different treatments to evaluate the influences of 650 induction and RKN infection on plant defense response 651 enzymes.

652 Both induction and inoculation improved PAL 653 activity, while increased enzyme activity caused by 654 induction only (IRCK) faster than nematode 655 inoculation ( $\mathrm{CKN}$ or IRN). PAL activity began to 656 drastically increase at 5dpi in IRCK. Compared with it, 657 the enzyme activity grew slowly at 5dpi in IRN, and 658 even more so, the activity of PAL was continuously 659 decreasing at the same time in CKN. In the latter two, 660 the activity started to elevate at 10dpi. Additionally, the 661 activity rose to peak simultaneously in all three 662 treatments at $15 \mathrm{dpi}$, and declined thereafter. At $25 \mathrm{dpi}$, 663 the activity was continuously falling in $\mathrm{CKN}$, or did 664 not change drastically in IRCK, while reached a small 665 maximum peak in IRN. In CKCK, the activity of PAL 666 had been continuously stable. Besides, before 667 inoculation, the changes of PAL activity had remained 


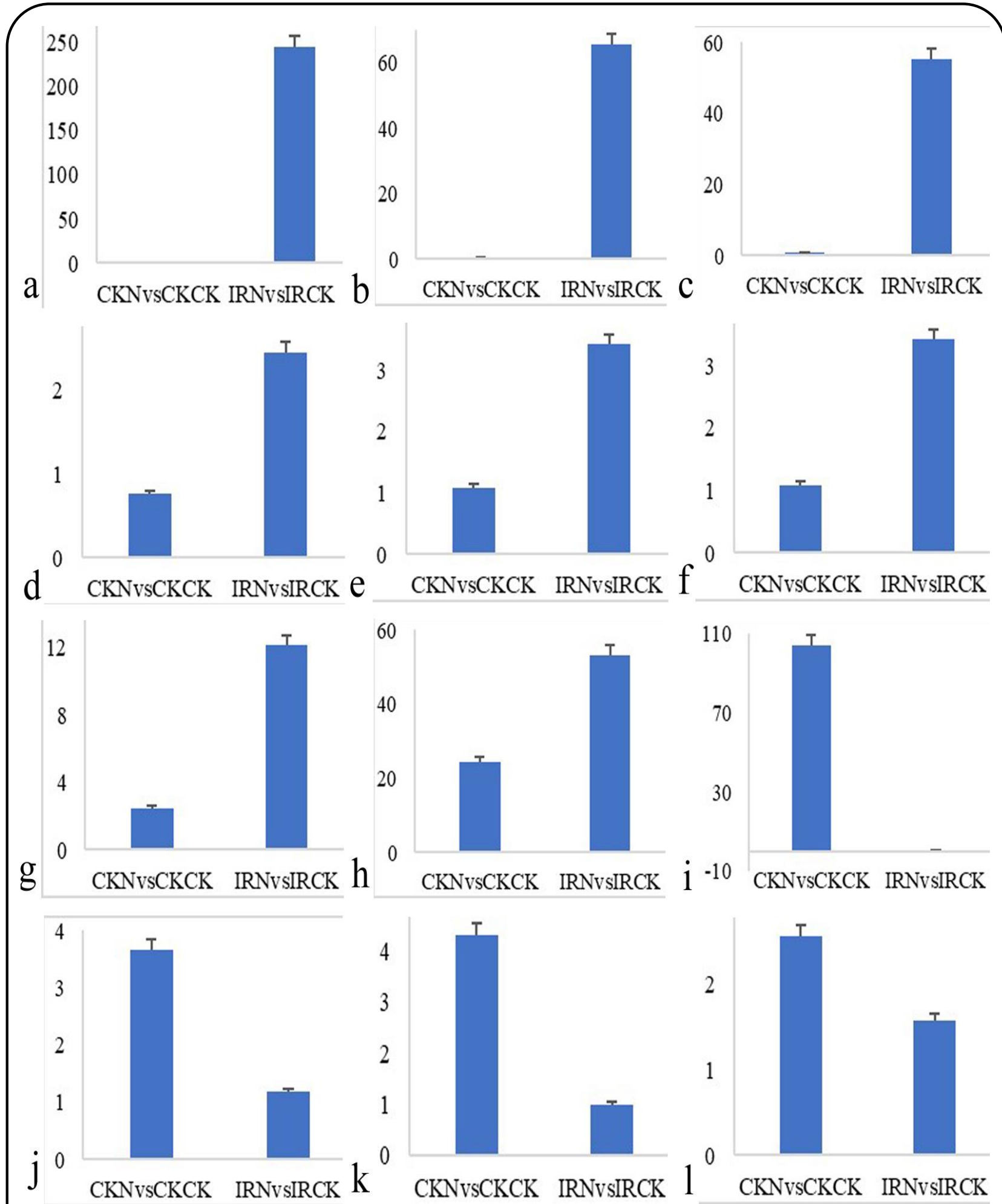

Fig. 5 Validation of RNA-seq data by RT-qPCR of selected genes from tomato subjected to RKN (Meloidogyne incognita) infection with or without induction. The bars indicate relative gene expression of the control values (CKN vs CKCK) in non-induced plants with or without inoculation and the treatment values (IRN vs IRCK) in induced plants with or without inoculation, respectively. (a) myb-related protein 315-1ike, (b) peroxidase P7-like, (c) putative disease resistance protein RGA4, (d) disease resistance protein RPP13-like, (e) auxin-responsive protein IAA, (f) $15.4 \mathrm{kDa}$ class V heat shock protein, (g) apoptosis-inducing factor homolog A-like, (h) extra-large guanine nucleotide-binding protein 1-like, (i) protein BREAST CANCER SUSCEPTIBILITY 1 homolog, (i) peroxidase 3, (k) probable glycosyltransferase 


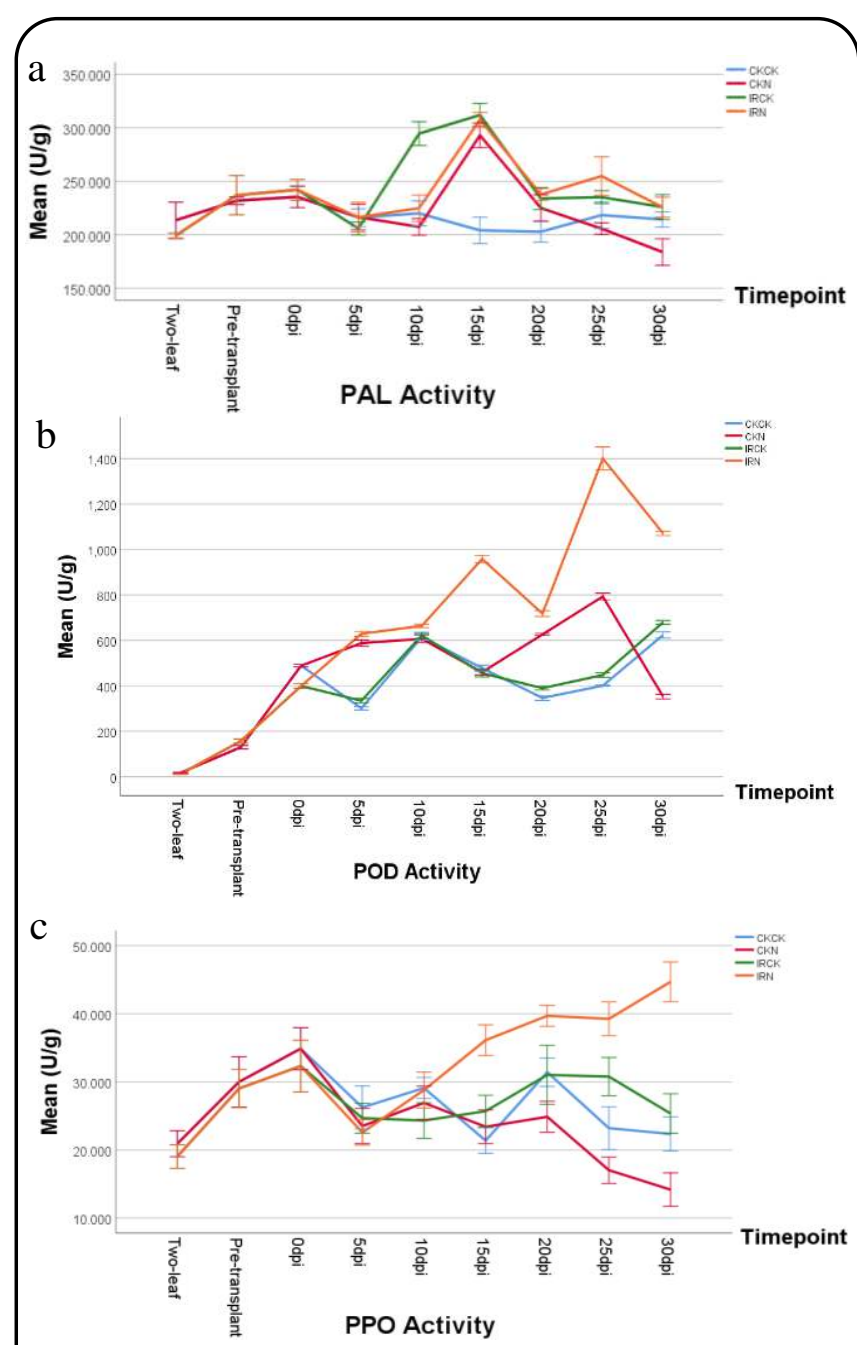

Fig.6 The activities of different enzymes, as measured in the crude extract prepared from roots harvested at various stages after $M$. incognita inoculation in Snef1216 induced plants (IRN), were compared with those in non-induced plants [1] and their respective mock-inoculated

669 gentle and had no significant differences in all 670 treatments. (Fig.6a)

671 The time-courses of peroxidase[4] activity were 672 similar between induction and control, just as between 673 IRCK and CKCK, or between IRN and CKN. Without 674 inoculation, there were two minimum peaks (5dpi and 675 20dpi) and one maximum peak (10dpi) in IRCK and $676 \mathrm{CKCK}$, and the whole values between the two 677 treatments were almost consistent. After inoculation, 678 the POD activity as a whole was higher than when no 679 nematodes were inoculated, and the activity in IRN 680 was further higher than that in CKN. The similarity of 681 the enzyme activities between IRN and CKN was that 682 they all indicated an early and sharp induction at 5dpi
683 and reached the maximum at $25 \mathrm{dpi}$, while the most 684 difference between the two treatments was at the 685 interval from 10dpi to 20dpi. The enzyme activity was 686 a maximum peak at $15 \mathrm{dpi}$ in IRN, while it reached a 687 minimum at the same time in CKN. (Fig.6b) The 688 activity of polyphenol oxidase (PPO) in IRN plants, 689 which was already high, began increasing after 5dpi 690 and thereafter elevated consistently up to 30dpi. 691 Although the activity of PPO was also higher in the 692 IRCK, it did not perform any evident promotion after 693 5dpi compared with control treatments (CKN and 694 CKCK). However, in no induction plants, the enzyme 695 was slightly increased at 10dpi but decreased 696 immediately until $15 \mathrm{dpi}$, and was continuing to decline 697 after 20dpi. (Fig.6c)

\section{Discussion}

699 At present, some studies have been conducted on the 700 molecular interaction between tomato and nematode, 701 and some progress has been made, while the research 702 is not thoroughly enough[ $\underline{35}, \underline{50}, \underline{51}]$. Studies 703 involving plant-nematode interactions provide an 704 opportunity to elucidating plant defense signaling in 705 root tissues, and this research field has usually received 706 little attention as yet. Here was the first study by omics 707 to research the mechanisms of induced resistance to 708 RKN and pathogenicity of RKN in the same variety 709 systematically, and to reflect plant autoimmunity to a 710 certain extent. To develop the autoimmune genes is to 711 develop a new disease-resistant breeding pathway, 712 which reduced the difficulty to some extent; which has 713 no instability just like transgenic technology, and 714 avoided the potential danger of transgenes to some 715 extent; to some extent, which avoided the 716 embarrassing situation that the fruit taste and the plant 717 resistance are opposite.

718 After examining the differential expression of 719 genes, it demonstrated that the down-regulated genes 720 were obviously more than the up-regulated, which is 721 similar with the findings of Schaff et al, who found 722 that after feeding sites (the position during 723 reproduction of nematode in roots and in infected roots 724 with mixed stage nematode) was established, there 725 were substantially less genes up-regulated than 726 repressed in tomato[35]. It was also consistent that the 727 conclusion made by Jammes et al. after analyzing 
DEGs in roots infected with RKN at weekly intervals post-infection in Arabidopsis[52].

For understanding the functional distribution of DEGs to better investigate the biological behavior of these responses, functional annotation and classification were implemented and generated. In IR-related group, the whole differential expression was from Map I_IR _unique that 12 up-regulated (mainly related to cell structure and amino acid related metabolism) and 32 down-regulated (mainly involving nucleic acid metabolism / glucose metabolism / JA metabolism related pathways) of GO terms, and one up-regulated (Ribosome) and one down-regulated (Photosynthesis-antenna proteins) of KEGG terms. In the case of NP-related group, the situation was similar in that GO enrichment was uniquely belonged to Map I. In addition, there were only 137 down-regulated, most of which were related to sugar metabolism, such as 'glyceraldehyde-3-phosphate metabolic process' / 'isoprenoid metabolic process' / 'pentose-phosphate shunt' / 'glucose 6-phosphate metabolic process' / 'pyruvate metabolic process' / 'starch metabolic process' / 'maltose metabolic process' / 'glucan metabolic process' / 'disaccharide metabolic process' / ' cellular polysaccharide metabolic process' / 'oligosaccharide metabolic process' / 'cellular carbohydrate metabolic process' . Furthermore, in this group, only two down-regulated KEGG pathways ('Linoleic acid metabolism' and 'alpha-Linolenic acid metabolism' ) were differentially expressed. In the BR-related group, among the GO terms of differential expression, it found that the only 2 up-regulated were associated with transcription factors, and the down-regulated 85 items were almost all related to plant defense. Among the differential expressed KEGG pathways, up- and down-regulated respectively were 5 (the most significant were phytohormone signaling and phenylpropanoid metabolism) and 11 terms (mainly involving energy metabolism: photosynthesis and metabolism of three major nutrients including sugar/fat/amino acid).

The tomato genes Mi-1.2 (Solanum lycopersicum) for resistance to three major RKNs, Meloidogyne arenaria, Meloidogyne javanica, and Meloidogyne incognita[53], which triggers hypersensitive response or localized tissue necrosis, was the first
774 RKN-resistance gene to be cloned[22]. It is a member 775 of the NBS- LRR family and located on chromosome 776 6[24]. To date, it has reported 9 tomato genes of the $\mathrm{Mi}$ 777 family[54]. In this study, Mi-1.2 (Solyc06g008480.1) 778 showed induction specifically during the control of $M$. 779 incognita infection in Snef1216-induced tomato roots, 780 suggesting that induction was useful against RKN. $781 \mathrm{Mi}-1.2$ is a resistance gene which could offer a 782 significant fitness benefit under heavy pressure of 783 nematode in tomato, just like Corbett et al. had found.

784 Under heavy pressure of nematode (200,000 eggs per 785 plant), the fruit production of plants carrying $M i-1.2$ 786 was ten-fold greater than that of plants which was 787 susceptible to nematode, and the seed production in 788 lifetime was almost forty-fold greater in 789 greenhouse[55]. At present, in commercially available 790 tomato cultivars, only the $M i$ gene conferred the 791 resistance to RKN[23], and was used exclusively for 79260 years[21]. Therefore, to discover and exploit novel 793 nematode resistance genes is critical for nematode 794 management.

$795 \quad H s p 90$ (heat shock protein 90) which is famous for 796 participating early in resistance gene signaling 797 pathways has a critical role in disease-resistant 798 signals[56, 57]. It has indicated that Hsp90 in 799 solanaceous plants are necessary for specific 800 R-gene-mediated resistance responses using 801 virus-induced gene silencing (VIGS). For instance, $802 H s p 90$ is required for the full function of $R x$-mediated

803 Potato virus $X$ resistance, $N$ that provides resistance to 804 TMV, Pto-mediated resistance to Pseudomonas 805 syringae expressing AvrPto, and Mi-1 that confers 806 resistance to potato aphid (Meloidogyne euphorbiae) 807 and nematode (Meloidogyne javanica) in 808 tomato[57-60]. Thus, the up-regulated Hsp90 of 809 IR-related group in this study may also be required for 810 Mi-1.2 mediated resistance to M. incognita in tomato.

811 It was confirmed that the expression of 812 glycosyltransferase was the requirement to the 813 expression of the resistance phenotype to RKN by a 814 VIGS approach[35]. In addition, it might act in an 815 all-or-nothing manner, or it might function (or not) to 816 effect resistance via a threshold effect, perhaps as some 817 sort of switch. Glycosyltransferases also have a role in 818 the synthesis of cell wall[ $[61, \underline{62}]$, and may imply a role 819 in resistance to RKN via this function. In this study, 
820 the differentially expressed glycosyltransferase was 821 only present in NP-related group, and was 822 down-regulated.

823 Expression of genes encoding MYB and WRKY 824 transcription, factors also seems to be related to the 825 priming of defense-related processes in 826 Snef1216-induced tomato roots with M. incognita 827 inoculation, since they were upregulated in IR-related 828 group, and were downregulated in NP-related group. 829 The differences in the number of MYB domain repeats 830 contained in the proteins of MYB family determine 831 their DNA-binding ability, which in turn affects their 832 functions[63]. They play a key role in several 833 processes, such as regulation of secondary 834 metabolism[64]. In Arabidopsis, AtMYB44 regulated 835 plant defense responses and was pertinent in tolerance 836 to acetylation in the ethylene-signaling pathway after 837 treatment with a harpin protein which was from a 838 bacterial pathogen[65], or caused higher antioxidant 839 enzyme activity and a stronger ROS burst in 840 AtMYB44-overexpressing transgenes compared to 841 wildtype plants following infection with Botrytis[66], 842 such functions may be associated with induced 843 resistance to root knot nematodes.

844 Other defense-related genes such as those encoding 845 PIs (proteinase inhibitors, namely PR-6) were also 846 specifically induced in the IR-related group 847 (Solyc08g080630.2: Up2.4661). Currently, using 848 proteinase inhibitors is one of the most advanced 849 strategies to defense against nematode, which could 850 hinder nematode feeding cell development by 851 interaction with the digestive system. These protease 852 inhibitors are usually found in plant seeds and are 853 proteins that interfere with digestive enzymes. Both the 854 application of a promoter which was up-regulated and 855 the application of PIs which were specific properly for 856 nematode proteinases[67], could obviously impact the 857 possible system that may regulate the activity of 858 "constitutive" promoter, that is, the promoter was 859 down-regulated locally where (feeding sites) its 860 activity was required, to prevent the production of PIs' 861 effective levels[68]. The most of these nematode 862 resistance proteins should hardly have impact on cells 863 in plant, and therefore there was no necessary to 864 restrict expression to feeding cells. The shortcomings 865 of this method might be to take advantage of virulent
866 pathotypes overcoming the influence of nematode 867 resistance proteins (unlikely for collagenase) or a 868 specificity that was limited to correct nematode species 869 under certain circumstances[69].

870 While the responses of incompatible interactions 871 are triggered in resistant plants or resistance-treated 872 plants, a series of basal defense responses of 873 compatible interactions are initiated in susceptible 874 plants[35]. Even if they show analogous expression 875 profiles, the occurrence of inducing defense genes in 876 compatible interactions was later than that in 877 incompatible interactions. For example, in the 878 compatible interaction between tomato plants and 879 Verticillium dahliae, the basal defense responses were 880 activated, and lead to great amount of plant pathogen 881 interaction, phenylalanine metabolism and 882 phenylpropanoid biosynthesis, and plant hormone 883 signal transduction being induced in tomato[70]. Our 884 results show a similar activation of basal defense 885 response-related genes, suggesting that there may be 886 overlap among the susceptible responses of tomato to 887 fungal pathogens and nematode. In addition, the 888 induced resistance treatment may also launch a basal 889 defense response before inoculation with nematode in 890 plant, just as the forming of a symbiont between 891 mycorrhizal fungi AMF and plants in tomato is thought 892 to predispose the mycorrhizal roots to a more efficient 893 or rapid activation of defense mechanisms after being 894 attacked by a pathogen subsequently, in a way similar

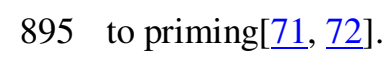

896 Besides transcription level, the possible roles of 897 induction and inoculation at the translational level, 898 namely the involvement of different important defense 899 enzymes, were also studied and compared between 900 different treatments to evaluate the influences of 901 induction and RKN infection on plant defense response 902 enzymes to support our findings. Plants can secure 903 themselves against phytopathogenic agents by 904 generating a wide range of antimicrobial compounds 905 among which defense-related enzymes, such as 906 phenylalanine ammonia lyase (PAL), peroxidase [4] 907 and polyphenol oxidase (PPO), have been involved in 908 cellular protection and disease resistance, and have 909 been indicated the role in the induction of systemic 910 resistance[73-76]. PAL, POD and PPO are enzymes 911 important in the biosynthesis of phenolic compounds 
912 and lignin, which are not only necessary during plant

913 development, but also are essential in establishing

914 defense against various stresses[77].

915 PAL is a mediator which involving the biosynthesis

916 of lignin, and is the first important enzyme catalyzing

917 various phenylpropanoid products synthesis from

918 phenylalanine, and is with high expression in resistant

919 plants which have infested, and has been participated

920 in resistance to insect[78]. These phenylpropanoid

921 polymers could be part component of the cell wall

922 structure which could resist the stylet of parasitic

923 nematode through primary physical defense, due to the

924 cell wall could play a role of a protectant to wound, a

925 physical barrier against certain infections, UV damage

926 and flavonoid pigments[79]. The first step which

927 catalyzed by PAL is a regulatory step of the

928 deamination response from phenylalanine to cinnamic

929 acid in the phenylpropanoid pathway. This reaction

930 produced many products involve the resistance to

931 pathogen, including lignin, coumarin, condensed

932 tannins, flavonoids and salicylic acid (SA) as a

933 signaling molecule[80].

934 POD (PR-9), which is a key enzyme in the

935 biosynthesis of lignin, functions as part of an

936 antioxidant system and represents one of the

937 components of the early defense system invaded by

938 pathogen and pest in host plant, involving degradation

939 of cytotoxic levels of hydrogen peroxide generated in

940 plant tissues due to pathogen and pest attack[81].

941 Furthermore, it could also be a catalyst to oxidize

942 phenolic compounds, whose accumulation activates a

943 cellular oxidative burst, which is not only toxic to the

944 host but also necessary for resistance against pathogens

945 and pests. POD are further in charge of the

946 cross-linking of the components of cell wall with

947 repression to nematode infestation[ $\underline{76}, \underline{82}]$. It was that

948 the combination of the properties of peroxidase

949 supplied evidence that POD may involve the formation

950 of barrier substances to limit the extent to which the

951 nematodes can feed on an induced resistant plant. In

952 this study, the POD activity of IRN was significantly

953 enhanced compared with other treatments, while

954 peaked at $15 \mathrm{dpi}$ and $25 \mathrm{dpi}$ when a large number of

955 nematodes had invaded the roots. Thus, the high POD

956 activity could not prevent nematode infestation

957 completely, however, it could be used as an early
958 physiological indicator to determine whether the host 959 was infected with $M$. incognita in tomato.

960 Plants are capable of protecting themselves from 961 phytopathogenic agents by generating a majority of 962 antimicrobial compounds among which 963 defense-related oxidoreductases, just like POD and 964 polyphenol oxidase (PPOs), have been participated in 965 protection and disease resistance in cell[ $[\underline{81}, \underline{83}]$. PPO 966 acts as a catalyst to the oxidation of phenolic 967 compounds to highly toxic quinones and tannins, 968 which are toxic to the growth of pathogenic mycelium. 969 In addition, since phenolic substances are precursors of 970 lignin formation in the cell, PPO can promote the 971 synthesis of lignin from phenols and accelerate cell 972 wall lignification against pathogens which play a 973 crucial role in plant disease resistance[84, 85]. The 974 change of PPO activity is related to disease resistance, 975 and pathogen infection and other external stimuli could 976 induce to elevate PPO activity. The PPO activity of 977 most resistant varieties or sensitive varieties after 978 induction is significantly increased after 979 inoculation[75]. The biosynthesis of POD and PPO 980 plays an important role in determining the degree of 981 host resistance in primed plants with beneficial 982 microbes[6-89].

\section{Conclusion}

984 In conclusion, by concentrating on differentially 985 expressed genes in the IR-related, NP-related and 986 BR-related groups based on RNA-seq approach, new 987 insights were discovered into the molecular 988 mechanisms that underlay the Penicillium 989 chrysogenum Snef1216-induced resistance against $M$. 990 incognita, nematode pathogenicity and basal resistance, 991 respectively. Comparative transcriptome analysis can 992 supply significant insights into the global changes in 993 gene expression following induction and nematode 994 infection. RT-qPCR was applied to validate the 995 RNA-seq output, and the enzymes which were 996 participated in defense response had also been 997 analyzed to support our discovery. The higher 998 expressed defense-related genes specifically in the 999 biocontrol interaction, requires the existence of defense 1000 responses primed by the induction of $P$. chrysogenum, 1001 as has been proposed for the interaction between $P$. 1002 chrysogenum and other types of pathogens $[10, \underline{11}, \underline{16}$, 
1003 17]. It will be advantage to the understanding of the 1004 interactions between plant and nematode, and serve for 1005 the breeding of nematode resistance cultivars that the 1006 illustration of the molecular resistance basic. The 1007 breeding of disease resistance cultivar is the most 1008 efficient method for the control of RKN, especially in 1009 Solanaceous plants[21]. These findings could 1010 contribute to the breeding of new tomato cultivars 1011 which are resistant to nematode. Overall, within an 1012 integrated and more sustainable management approach, 1013 the application of biocontrol organisms, like $P$. 1014 chrysogenum, seems to be a prospective alternative.

\section{Supplementary Data}

Supplementary Table S1. Differentially expressed genes of induced resistance-related groups in Snef1216-induced plants following inoculation of M. incognita.

Supplementary Table S2. Differentially expressed genes of nematode pathogenesis-related groups in control plants following compatible interaction with M. incognita.

Supplementary Table S3. Differentially expressed genes in basal resistance-related groups.

Supplementary Table S4. Differentially regulated genes associated with resistant and susceptible responses of eight categories in Snef1216-induced and control plants infected with $M$. incognita. Supplementary Table S5. Primers used in RT-qPCR validation of gene expression analysis.

1016

\section{Competing Financial Interests}

1017 All authors declare that they have no competing 1018 financial interests.

\section{Abbreviation}

1020

1021

1022

1023

1024

1025

1026

1027

1028

1029

1030

1031

1032

RKN: root-knot nematode; AS: alternative splicing; DEG: differentially expressed gene; IR: induced resistance; NP: nematode pathogenesis; BR: basal resistance; NB/LRR: nucleotide-binding/leucine-rich repeat; J2: second-stage juveniles; CKCK: negative control; CKN: pathogen control; IRCK: inducer control; IRN: pathogen + inducer; dpi: days post inoculation; G0: Gene Ontology; KEGG: Kyoto Encyclopedia of Genes; PPI: protein-protein interactions; RABT: reference annotation-based transcript; SNP: single nucleotide polymorphism; RT-qPCR: quantitative real-time PCR; PAL: phenylalanine ammonia lyase; POD: peroxidase; PPO: polyphenol oxidase; PIs: proteinase inhibitors.

\section{Acknowledgements}

1034 The research was funded by Special Fund for 1035 Agro-scientific Research in the Public Interest 1036 (201103018), National Natural Science Foundation of 1037 China (31171823).

\section{Authors' Contributions}

1039 M.Z. and Y.D. conceived and designed the experiments. 1040 M. Z. performed the experiments, analyzed the data, and 1041 wrote the paper. A.S., X.Z., Y.W., X. L., H.F., Y.X., 1042 L.C. and Y. D. modified the article. All authors read 1043 and approved the final manuscript.

\section{Author details}

$1045{ }^{1}$ Nematology Institute of Northern China, Shenyang 1046 Agricultural University, Shenyang 110866, Liaoning, 1047 China. ${ }^{2}$ College of Biosciences and Biotechnology, 1048 Shenyang Agricultural University, Shenyang 110866, 1049 Liaoning, China. ${ }^{3}$ College of Science, Shenyang 1050 Agricultural University, Shenyang 110866, Liaoning, 1051 China. ${ }^{4}$ College of Plant Protection, Shenyang 1052 Agricultural University, Shenyang 110866, Liaoning, 1053 China.

1054 Received: Accepted:

1055 Published:

\section{References}

1057 1. Yeckel G, Ithal N, Nettleton D, Recknor J, Wu XR, 1058 Nguyen HT, Mitchum MG: Characterization of 1059 1060 1061 1062 1063

1064 1065 1066 1067 1068

1069

1070

1071

1072

1073

1074

1075

1076 soybean genes involved in soybean cyst nematode (SCN) resistance [abstract]. 2007.

2. Good JM, Smart J, G. C, Perry VG: Relation of plant parasitic nematodes to soil management practices. Tropical Nematology 1968.

3. Wesemael WML, Viaene N, Moens M: Root-knot nematodes (Meloidogyne spp.) in Europe. Nematology 2011, 13(1):3-16.

4. Dutta S, Rani TS, Podile AR: 247.Root Exudate-Induced Alterations in Bacillus cereus Cell Wall Contribute to Root Colonization and Plant Growth Promotion. PloS one 2013, 8(10):e78369.

5. Vos C, Broucke DVD, Lombi FM, Waele DD, Elsen A: Mycorrhiza-induced resistance in banana acts on nematode host location andpenetration. Soil Biology \& Biochemistry 2012, 47(2):60-66.

6. Loon LCV: Induced resistance in plants and the role of pathogenesis-related proteins. European Journal of Plant Pathology 1997, 103(9):753-765.

7. Sergio M: Natural genetic and induced plant 

nematodes alternative to pesticides. Plant Cell Reports 2011, 30(3):311-323.

8. Thürig B: The effect of an extract from mycelium of Penicillium chrysogenum on plant-pathogen interactions and characterisation of elicitors in this extract. 2004.

9. Marx F, Binder U, Leiter É, Pócsi I: The Penicillium chrysogenum antifungal protein $\mathrm{PAF}$, a promising tool for the development of new antifungal therapies and fungal cell biology studies. Cellular and Molecular Life Sciences 2008, 65(3):445-454.

10. Chen S, Dong H, Fan Y, Li W, Cohen Y: Dry mycelium of Penicillium chrysogenum induces expression of pathogenesis-related protein genes and resistance against wilt diseases in Bt transgenic cotton. Biological Control 2006, 39(3):460-464.

11. Dong H, Li W, Zhang D, Tang W: Differential expression of induced resistance by an aqueous extract of killed Penicillium chrysogenum against Verticillium wilt of cotton. Crop Protection 2003, 22(1):129-134.

12. Jian WU, Jun HE, Xiang-Jun LI, Wang JM, Yuan-Xian Z, Zhang TJ, Yin ZR, Yan CL: Study Control Effect of Induced-resistance Activator and Bio-control Agents on Tobacco. Journal of Kunming University 2015.

13. Whipps JM: Prospects and limitations for mycorrhizas in biocontrol of root pathogens. Canadian Journal of Botany 2011, 82(8):1198-1227.

14. Dong $\mathrm{H}$, Cohen Y: Induced resistance in cotton seedlings against fusarium wilt by dried biomass of Penicillium chrysogenum and its water extract. Phytoparasitica 2002, 30(1):77-87.

15. Thuerig B, Felix G, Binder A, Boller T, Tamm L: An extract of Penicillium chrysogenum elicits early defense-related responses and induces resistance in Arabidopsis thaliana independently of known signalling pathways. Physiological \& Molecular Plant Pathology 2006, 67(3-5):180-193.

16. Wang B, Liu H, Cai C, Thabit M, Wang P, Li G, Duan Z: Effect of dry mycelium of Penicillium chrysogenum fertilizer on soil microbial community composition, enzyme activities and snap bean growth. Environmental Science and
1126

1127

1128

1129

1130

1131

1132

1133

1134

1135

1136

1137

1138

1139

1140

1141

1142

1143

1144

1145

1146

1147

1148

1149

1150

1151

1152

1153

1154

1155

1156

1157

1158

1159

1160

1161

1162

1163

1164

1165

1166

1167

1168

1169

1170

1171
Pollution Research 2016, 23(20):20728-20738.

17. Xu X, Zhang Z, Huang Q, Chen W: Biosorption performance of multi-metal resistant fungus Penicillium chrysogenum XJ-1 for removal of $\mathrm{Cu} 2+$ and Cr6+ from aqueous solutions. Geomicrobiology 2017(1).

18. Zhong Y, Peng JJ, Chen ZZ, Xie H, Luo D, Dai JR, Yan F, Wang JG, Dong HZ, Chen SY: Dry mycelium of Penicillium chrysogenum activates defense responses and restricts the spread of Tobacco Mosaic Virus in tobacco. Physiological \& Molecular Plant Pathology 2015, 92:28-37.

19. Gotlieb D, Oka Y, Ben-Daniel B-H, Cohen Y: Dry mycelium of Penicillium chrysogenum protects cucumber and tomato plants against the root-knot nematode Meloidogyne javanica. Phytoparasitica 2003, 31(3):217-225.

20. Siddiqui ZA, Sayeed AM: Effects of antagonistic fungi, plant growth-promoting rhizobacteria, and arbuscular mycorrhizal fungi alone and in combination on the reproduction of Meloidogyne incognita and growth of tomato. Journal of General Plant Pathology 2009, 75(2):144.

21. Mao Z, Zhu P, Liu F, Huang Y, Ling J, Chen G, Yang Y, Feng D, Xie B: Cloning and functional analyses of pepper CaRKNR involved in Meloidogyne incognita resistance. Euphytica 2015, 205(3):903-913.

22. Milligan SB, Bodeau J, Yaghoobi J, Kaloshian I, Zabel P, Williamson VM: The Root Knot Nematode Resistance Gene Mi from Tomato Is a Member of the Leucine Zipper, Nucleotide Binding, Leucine-Rich Repeat Family of Plant Genes. Plant Cell 1998, 10(8):1307-1319.

23. Huang X, Mcgiffen M, Kaloshian I: Reproduction of Mi-Virulent Meloidogyne incognita Isolates on Lycopersicon spp. Journal of Nematology 2004, 36(1):69-75.

24. Ammiraju JS, Veremis JC, Huang X, Roberts PA, Kaloshian I: The heat-stable root-knot nematode resistance gene Mi-9 from Lycopersicon peruvianum is localized on the short arm of chromosome 6. Tagtheoretical \& Applied Geneticstheoretische Und Angewandte Genetik 2003, 106(3):478-484.

25. Fellers JP, Tremblay D, Handest MF, Lommel SA: 
The Potato virus $Y \mathbf{M}(\mathbf{S}) \mathbf{N}(\mathrm{R})$ NIb-replicase is the elicitor of a veinal necrosis-hypersensitive response in root knot nematode resistant tobacco. Molecular Plant Pathology 2002, 3(3):145.

26. Mao Z, Zheng J, Wang Y, Chen G, Yang Y, Feng D, $\mathrm{Xie} \mathrm{B}$ : The new CaSn gene belonging to the snakin family induces resistance against root-knot nematode infection in pepper. Phytoparasitica 2011, 39(2):151-164.

27. Bleve-Zacheo T, Bongiovanni M, Melillo MT, Castagnone-Sereno P: The pepper resistance genes Me1 and Me3 induce differential penetration rates and temporal sequences of root cell ultrastructural changes upon nematode infection. Plant Science 1998, 133(1):79-90.

28. Djian-Caporalino C, Fazari A, Arguel MJ, Vernie T, Vandecasteele C, Faure I, Brunoud G, Pijarowski L, Palloix A, Lefebvre V: Root-knot nematode (Meloidogyne spp.) Me resistance genes in pepper (Capsicum annuum L.) are clustered on the P9 chromosome. Theoretical \& Applied Genetics 2007, 114(3):473-486.

29. Wang C, Ulloa M, Roberts P: A transgressive segregation factor (RKN2) in Gossypium barbadense for nematode resistance clusters with gene rkn1 in G-hirsutum. Molecular Genetics \& Genomics 2008, 279(1):41-52.

30. Zhang B, Yang Y, Wang J, Ling X, Hu Z, Liu T, Chen T, Zhang W: A CC-NBS-LRR type gene GHNTR1 confers resistance to southern root-knot nematode in Nicotiana.benthamiana and Nicotiana.tabacum. European Journal of Plant Pathology 2015, 142(4):715-729.

31. Wubben M, Callahan FE, Jenkins JN, Velten J: OVER-EXPRESSION OF MIC3 REDUCES COTTON SUSCEPTIBILITY TO ROOT-KNOT NEMATODE. Journal of Nematology 2012, 44(4):497-498.

32. Claverie M, Dirlewanger E, Cosson P, Bosselut N, Lecouls AC, Voisin R, Kleinhentz M, Lafargue B, Caboche M, Chalhoub B: High-resolution mapping and chromosome landing at the root-knot nematode resistance locus Ma from Myrobalan plum using a large-insert BAC DNA library. Tagtheoretical \& Applied Geneticstheoretische Und Angewandte Genetik 2004, 109(6):1318-1327.
1218

1219

1220

1221

1222

1223

1224

1225

1226

1227

1228

1229

1230

1231

1232

1233

1234

1235

1236

1237

1238

1239

1240

1241

1242

1243

1244

1245

1246

1247

1248

1249

1250

1251

1252

1253

1254

1255

1256

1257

1258

1259

1260

1261

1262
33. Chen R, Li H, Zhang L, Zhang J, Xiao J, Ye Z: CaMi, a root-knot nematode resistance gene from hot pepper (Capsium annuum L.) confers nematode resistance in tomato. Plant Cell Reports 2007, 26(7):895-905.

34. Doyle EA, Lambert KN: Meloidogyne javanica chorismate mutase 1 alters plant cell development. Molecular plant-microbe interactions : MPMI 2003, 16(2): 123.

35. Schaff JE, Nielsen DM, Smith CP, Scholl EH, Bird DM: Comprehensive Transcriptome Profiling in Tomato Reveals a Role for Glycosyltransferase in Mi-Mediated Nematode Resistance. Plant Physiology 2007, 144(2):1079.

36. Jiang MY, Duan YX, Chen LJ, Zhu XF: Study on the Fermentation of Penicillium Snef1216 Inducing the Resistance of Tomato to Root-knot Nematode. Journal of Henan Agricultural Sciences 2011.

37. Yao Q: Resistance against in tomato induced by fermentation liquid of strain Snef1216. Acta Phytopathologica Sinica 2014, 44(6):693-699.

38. BAI Chunming DY, CHEN Lijie, LIU Yifei, ZHU Xiaofeng: Evaluation of Tomato Resistance to Meloidogyne incognita 番茄品种对南方根结线虫 的抗性评价. CHINA VEGETABLES 2010, 000(006):33-37.

39. Liu MM, Xing YM, Zhang DW, Guo SX: Transcriptome analysis of genes involved in defence response in Polyporus umbellatus with Armillaria mellea infection. Scientific Reports 2014, 5(3):575-581.

40. Oshlack MDYMJWGKSA: Gene ontology analysis for RNA-seq: accounting for selection bias Genome Biology 2010, 11:R14.

41. Minoru K, Susumu G: KEGG: Kyoto Encyclopedia of Genes and Genomes. Nucleic Acids Research 2000(1):29-34.

42. Minoru, Kanehisa, Yoko, Sato, Miho, Furumichi, Kanae, Morishima, Mao, Tanabe: New approach for understanding genome variations in KEGG. Nucleic Acids Research 2018, 47:D590-D595.

43. Kanehisa M: Toward understanding the origin and evolution of cellular organisms. Protein Science 2019, 28:1947-1951.

44. b KJLaTDS: Analysis of Relative Gene Expression Data Using Real-Time Quantitative PCR and the 

408.

45. Chen J, Fernandez D, Wang DD, Chen YJ, Dai GH: Biological control mechanisms of D-pinitol against powdery mildew in cucumber. Physiological and Molecular Plant Pathology 2014, 88(0):52-60.

46. YAN Honghai ZZ, WANG Yan, GUO Shuqiong, XIA Shuchun , CHI Shengqi: Change of Defense Enzymatic Activities after Treatment with Different Salicylic Acid in Peanut. $J$ ournal of Peanut Science 2006, 35(4):20-22.

47. Mohammadi M, Kazemi $\mathrm{H}$ : Changes in peroxidase and polyphenol oxidase activities in susceptible and resistant wheat heads inoculated with Fusarium graminearum and induced resistance. Plant Science 2002, 162(4):491-498.

48. Murray SL, Ingle RA, Petersen LN, Denby KJ: Basal resistance against Pseudomonas syringae in Arabidopsis involves WRKY53 and a protein with homology to a nematode resistance protein. Molecular plant-microbe interactions : MPMI 2007, 20(11):1431.

49. !!! INVALID CITATION !!!

50. Vos C, Schouteden N, van Tuinen D, Chatagnier O, Elsen A, De Waele D, Panis B, Gianinazzi-Pearson V: Mycorrhiza-induced resistance against the root-knot nematode Meloidogyne incognita involves priming of defense gene responses in tomato. Soil Biology and Biochemistry 2013, $\mathbf{6 0}(0): 45-54$.

51. Hwang CF, Williamson VM: Leucine-rich repeat-mediated intramolecular interactions in nematode recognition and cell death signaling by the tomato resistance protein Mi. Plant Journal 2003, 34(5):585.

52. Jammes F, Lecomte $P$, Engler J, Bitton F, Martin-Magniette M-L, Renou J-P, Abad P, Favery B: Genome-wide expression profiling of the host response to root-knot nematode infection in Arabidopsis, vol. 44; 2005.

53. Gilbert JC, Mcguire DC: Inheritance of resistance to severe root-knot from Meloidogyne incognita in commercial type tomatoes. 1956.

54. Jablonska B, Ammiraju JS, Bhattarai KK, Mantelin S, Martinez dIO, Roberts PA, Kaloshian I: The Mi-9 gene from Solanum arcanum conferring
1310

1311

1312

1313

1314

1315

1316

1317

1318

1319

1320

1321

1322

1323

1324

1326

1327

1328

1329

1330

1331

1332

1333

1334

1335

1336

1337

1338

1339

1340

1341

1342

1343

1344

1345

1346

1347

1348

1349

1350

1351

1352

1353

1354

1355 heat-stable resistance to root-knot nematodes is a homolog of Mi-1. Plant Physiology 2007, 143(2): 1044

55. Corbett BP, Jia L, Sayler RJ, Arevalo-Soliz LM, Goggin F: The effects of root-knot nematode infection and mi-mediated nematode resistance in tomato on plant fitness. Journal of Nematology 2011, 43(2):82-89.

56. Rui L, Isabelle $\mathrm{M}$, Peter $\mathrm{M}$, Ruiz MT, Jack $\mathrm{P}$, Ai-Jiuan W, Rathjen JP, Abdelhafid B, Louise D, Baulcombe DC: High throughput virus-induced gene silencing implicates heat shock protein 90 in plant disease resistance. Embo Journal 2003, 22(21):5690-5699.

57. Yule L, Tessa BS, Michael S, Suhua F, Dinesh-Kumar SP: Molecular chaperone Hsp90 associates with resistance protein $\mathbf{N}$ and its signaling proteins SGT1 and Rar1 to modulate an innate immune response in plants. Jbiolchem 2004, 279(3):2101-2108.

58. Picard D, . Heat-shock protein 90, a chaperone for folding and regulation. Cellular \& Molecular Life Sciences Cmls 2002, 59(10):1640-1648.

59. Hubert DA, Pablo T, Youssef B, Priti K, Akira T, Ken S, Dangl JL: Cytosolic HSP90 associates with and modulates the Arabidopsis RPM1 disease resistance protein. Embo Journal 2014, 22(21):5679-5689.

60. Akira T, Catarina C, Kazuya I, Ken S: HSP90 interacts with RAR1 and SGT1 and is essential for RPS2-mediated disease resistance in Arabidopsis. Proceedings of the National Academy of Sciences of the United States of America 2003, 100(20):11777-11782.

61. Lao NLD, Kiang S, Coupland G, Shoue DA, Carpita NC, Kavanagh TA: Mutation of a family 8 glycosyltransferase gene alters cell wall carbohydrate composition and causes a humidity-sensitive semi-sterile dwarf phenotype in Arabidopsis. Plant Molecular Biology 2003, 53(5):687-701.

62. Jack E, Michael ST, Naomi G, Peter U, Bent Larsen P: A complementary bioinformatics approach to identify potential plant cell wall glycosyltransferase-encoding genes. Plant Physiology 2004, 136(1):2609-2620. 
63. Dubos C, Stracke R, Grotewold E, Weisshaar B, Martin C, Lepiniec L: MYB transcription factors in Arabidopsis. Trends in Plant Science 2010, 15(10):573-581.

64. Jin H, ., Martin C, . Multifunctionality and diversity within the plant MYB-gene family. Plant Molecular Biology 1999, 41(5):577-585.

65. Liu R, Chen L, Jia Z, Lü B, Shi H, Shao W, Dong H: Transcription factor AtMYB44 regulates induced expression of the ETHYLENE INSENSITIVE2 gene in Arabidopsis responding to a harpin protein. Mol Plant Microbe Interact 2011, 24(3):377-389.

66. Shi H, Cui R, Hu B, Wang X, Zhang S, Liu R, Dong $\mathrm{H}$ : Overexpression of transcription factor AtMYB44 facilitates Botrytis infection in Arabidopsis. Physiological \& Molecular Plant Pathology 2011, 76(2):90-95.

67. Koritsas VM, Atkinson HJ: Proteinases of females of the phytoparasite Globodera pallida (potato cyst nematode). Parasitology 1994, 109(3):357-365.

68. Urwin PE, Atkinson HJ, Waller DA, Mcpherson MJ: Engineered oryzacystatin-I expressed in transgenic hairy roots confers resistance to Globodera pallida. Plant Journal 2010, 8(1):121-131.

69. Gheysen G, Walter VDE, Barthels N, Karimi M, Van Montagu M: The Exploitation of Nematode-Responsive Plant Genes in Novel Nematode Control Methods. Pest Management Science 2015, 47(1):95-101.

70. Tan G, Liu K, Kang J, Xu K, Yi Z, Hu L, Ju Z, Li C: Transcriptome analysis of the compatible interaction of tomato with Verticillium dahliae using RNA-sequencing. Front Plant Sci 2015, 6:428.

71. Dumas-Gaudot E, Gollotte A, Cordier C, Gianinazzil S, Gianinazzi-Pearson V: Modulation of Host Defence Systems; 2000.

72. Pozo* MJ, Verhage A, García-Andrade J, García JM, Azcón-Aguilar C: Priming Plant Defence Against Pathogens by Arbuscular Mycorrhizal Fungi. In: Mycorrhizas - Functional Processes and Ecological Impact. Edited by Azcón-Aguilar C, Barea JM, Gianinazzi S, Gianinazzi-Pearson V. Berlin, Heidelberg: Springer Berlin Heidelberg; 2009:
123-135.

1403 73. Youssef K, Sanzani SM, Ligorio A, Ippolito A, Terry

1404 LA: Sodium carbonate and bicarbonate
1405

1406

1407

1408

1409

1410

1411

1412

1413

1414

1415

1416

1417

1418

1419

1420

1421

1422

1423

1424

1425

1426

1427

1428

1429

1430

1431

1432

1433

1434

1435

1436

1437

1438

1439

1440

1441

1442

1443

1444

1445

1446 1447 treatments induce resistance to postharvest green mould on citrus fruit. Postharvest Biology and Technology 2014, 87(0):61-69.

74. Venter E, Mansoor CV, Sibisi P, Botha A-M: Potassium phosphate induces tolerance against the Russian wheat aphid (Diuraphis noxia, Homoptera: Aphididae) in wheat. Crop Protection 2014, 61(0):43-50.

75. Złotek U, Wójcik W: Effect of arachidonic acid elicitation on lettuce resistance towards Botrytis cinerea. Scientia Horticulturae 2014, 179(0):16-20.

76. Narendra Babu A, Jogaiah S, Ito S-i, Kestur Nagaraj A, Tran L-SP: Improvement of growth, fruit weight and early blight disease protection of tomato plants by rhizosphere bacteria is correlated with their beneficial traits and induced biosynthesis of antioxidant peroxidase and polyphenol oxidase. Plant Science 2015, 231(0):62-73.

77. Sumayo MS, Kwon D-K, Ghim S-Y: Linoleic acid-induced expression of defense genes and enzymes in tobacco. Journal of plant physiology 2014, 171(18):1757-1762.

78. Smith CM, Liu X, Wang LJ, Liu X, Chen MS, Starkey S, Bai J: Aphid Feeding Activates Expression of a Transcriptome of Oxylipin-based Defense Signals in Wheat Involved in Resistance to Herbivory. Journal of Chemical Ecology 2010, 36(3):260-276.

79. W Liang X, Dron M, L Cramer C, Dixon R, J Lamb $C$ : Differential regulation of phenylalanine ammonia-Iyase genes during plant development and by environmental cues, vol. 264; 1989.

80. Dixon R, Achnine L, Kota P, Liu C, Reddy M, Wang L: The phenylpropanoid pathway and plant defence-a genomics perspective. Mol Plant Pathol 2002, 3(5):371-390.

81. Thakker JN, Patel S, Dhandhukia PC: Induction of Defense-Related Enzymes in Banana Plants: Effect of Live and Dead Pathogenic Strain of Fusarium oxysporum f. $\quad$ sp. cubense. Isrn Biotechnology 2013, 2013(1).

82. Zhang J, Kirkham M B: Drought-Stress-Induced Changes in Activities of Supeoxide Dismutase, 
Catalase, and Peroxidase in Wheat Spesies. Plant and cell physiology 1994, 35(5):785-791.

83. Amil-Ruiz F, Blanco-Portales R, Muñoz-Blanco J, Caballero JL: The strawberry plant defense mechanism: a molecular review. Plant \& Cell Physiology 2011, 52(11):1873.

84. Asada Y, Ohguchi T, Matsumoto I: Biosynthesis of lignin in Japanese radish root infected by downy mildew fungus; 1976.

85. Richter C, Dirks ME, Gronover CS, Prüfer D, Moerschbacher BM: Silencing and heterologous expression of ppo-2 indicate a specific function of a single polyphenol oxidase isoform in resistance of dandelion (Taraxacum officinale) against Pseudomonas syringae pv. tomato. Mol Plant Microbe Interact 2012, 25(2):200-210.

86. Ramamoorthy V, Viswanathan R, Raguchander T, Prakasam V, Samiyappan R: Induction of systemic resistance by plant growth promoting rhizobacteria in crop plants against pests and diseases. Crop Protection 2001, 20(1):1-11.

87. Chowdappa P, Kumar SPM, Lakshmi MJ, Upreti KK: Growth stimulation and induction of systemic resistance in tomato against early and late blight by Bacillus subtilis OTPB1 or Trichoderma harzianum OTPB3. Biological Control 2013, 65(1):109-117.

88. Jogaiah S, Abdelrahman M, Tran LSP, Shinichi I: Characterization of rhizosphere fungi that mediate resistance in tomato against bacterial wilt disease. Journal of Experimental Botany 2013, 64(12):3829-3842.

89. Vanitha SC, Umesha S: Pseudomonas fluorescens mediated systemic resistance in tomato is driven through an elevated synthesis of defense enzymes. Biologia Plantarum 2011, 55(2):317-322. 


\section{Figures}

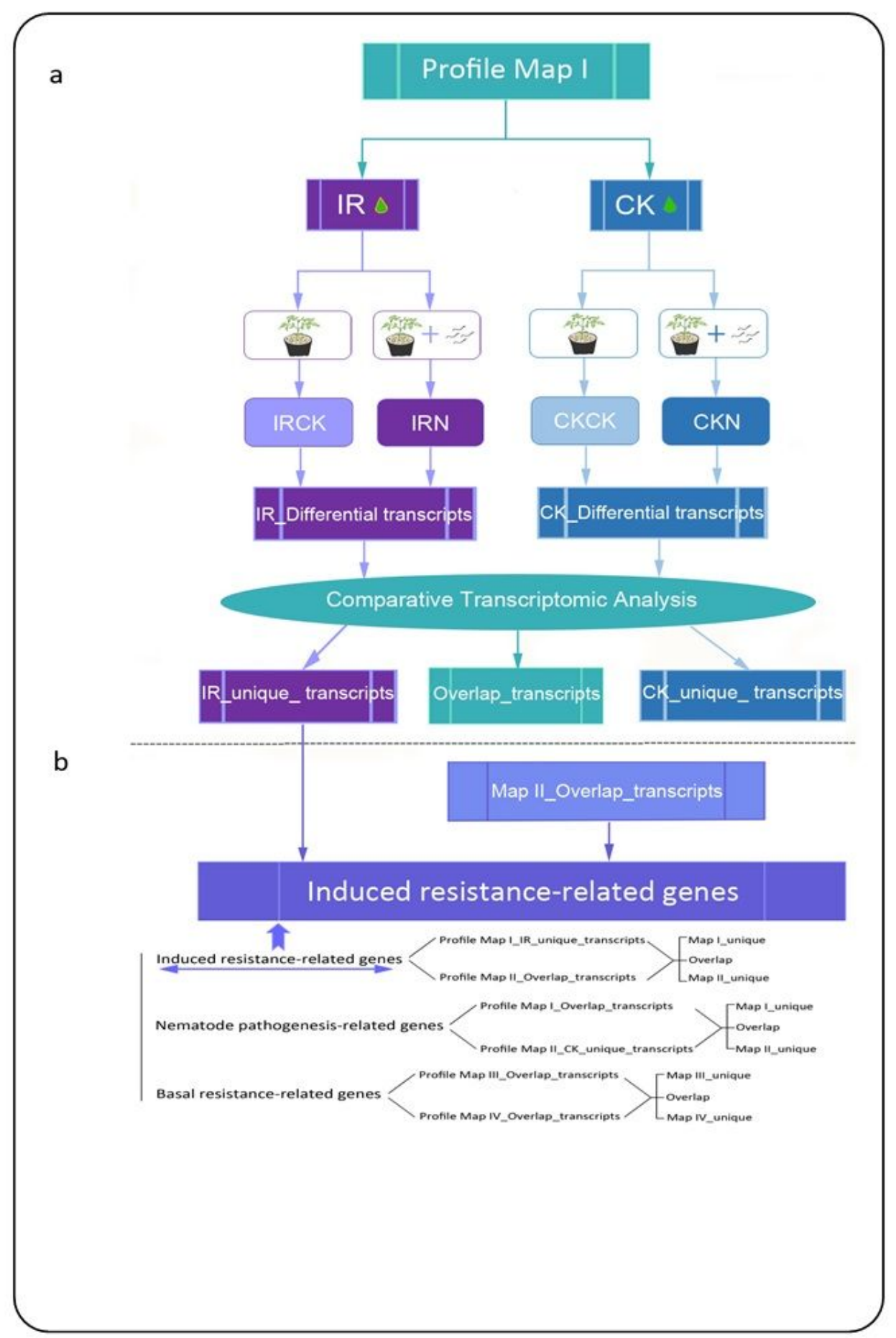

\section{Figure 1}

a. One of the profile maps for comparative transcriptomic analysis, namely profile map I- (IRN vs IRCK) vs (CKN vs CKCK). Firstly, constructed mRNA-seq libraries of different treatments; Secondly, generated transcriptome data of each mRNA library; Thirdly, obtained differential transcripts of induced resistant 
(IR) group and control (CK) group, respectively; Finally, comparatively analyzed between the IR and CK groups, and obtained their own and shared transcripts. The remaining few were profile map II- (IRCK vs CKCK) vs (IRN vs CKN), profile map III- (IRCK vs CKCK) vs (CKN vs CKCK), profile map IV- (IRCK vs CKCK) vs (IRN vs IRCK), respectively. b. Graphic presentation of the mapping design of results analysis.

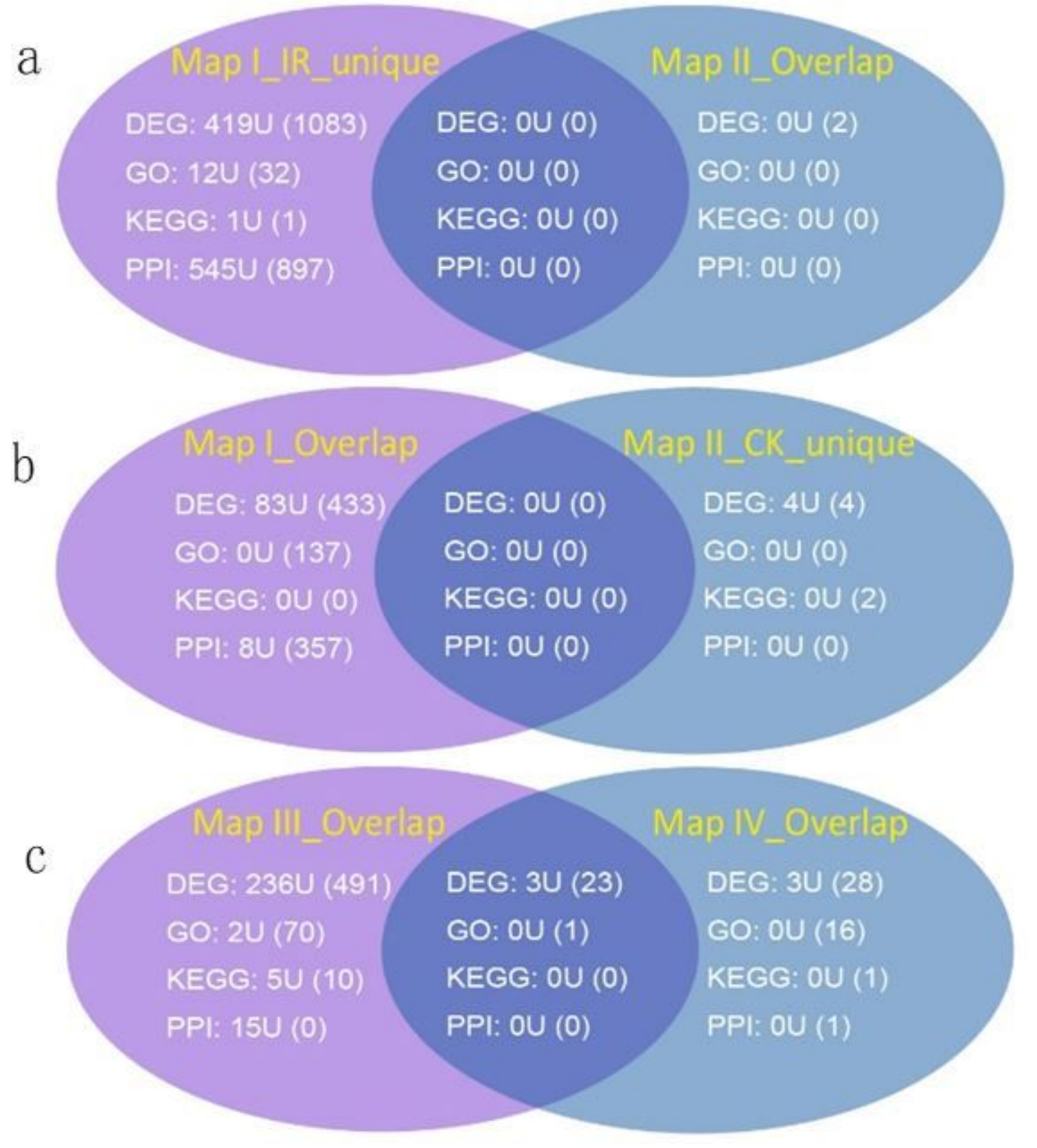

\section{Figure 2}

Venn diagrams of differential transcripts in (a) induced resistance-related, (b) nematode pathogenesisrelated and (c) basal resistance-related groups following $\mathrm{M}$. incognita inoculation at 15 day post inoculation (dpi). Numbers in parentheses indicate down-regulated genes; $U$, upregulated genes. 
a.

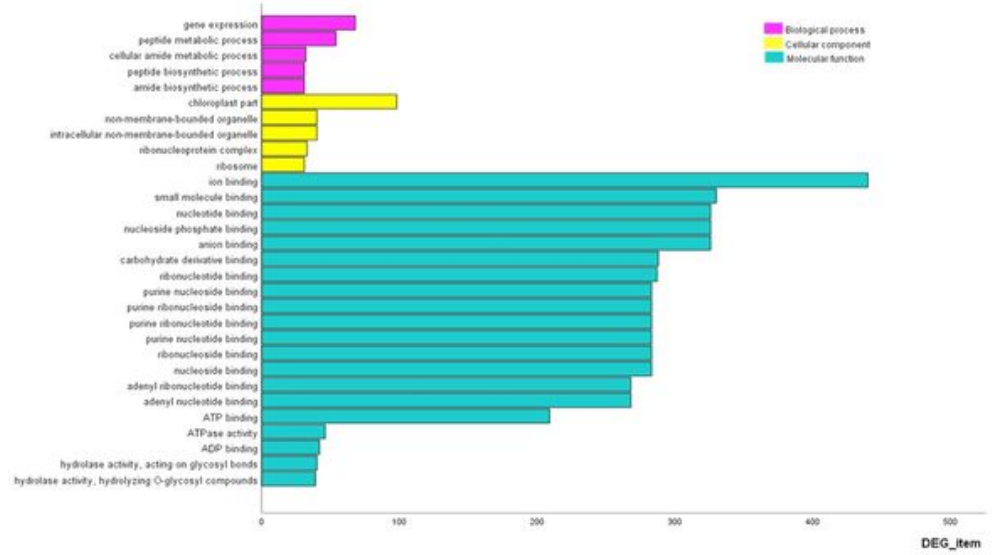

b.

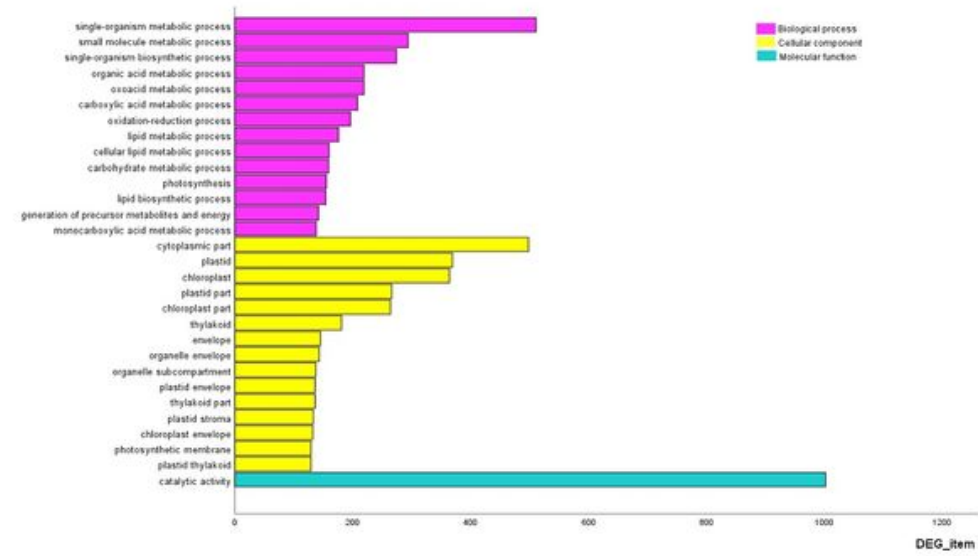

c.

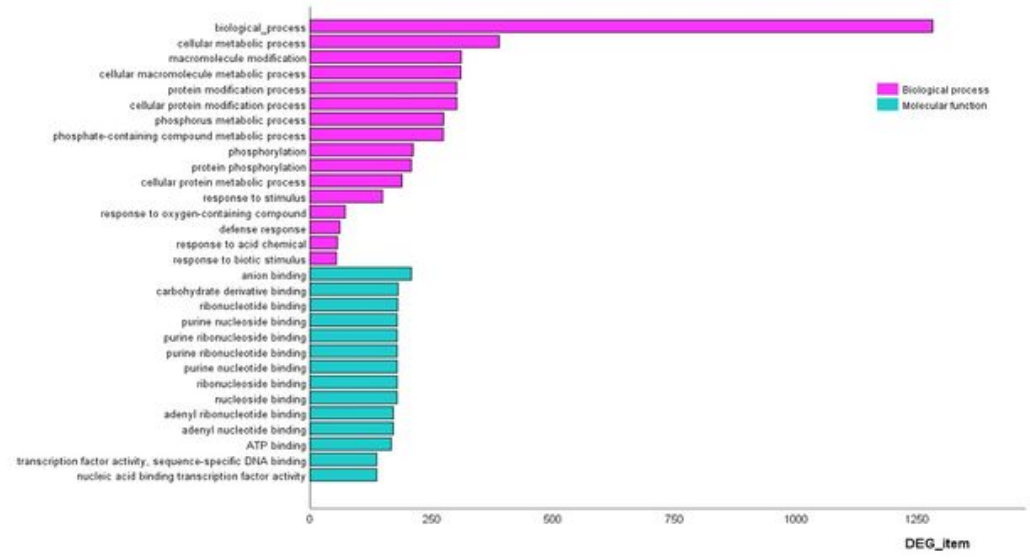

Figure 3

GO annotations of differentially expressed genes (a) GO annotation related to induced resistance, (b) GO annotation related to nematode pathogenesis and (c) GO annotation related to basal resistance. 


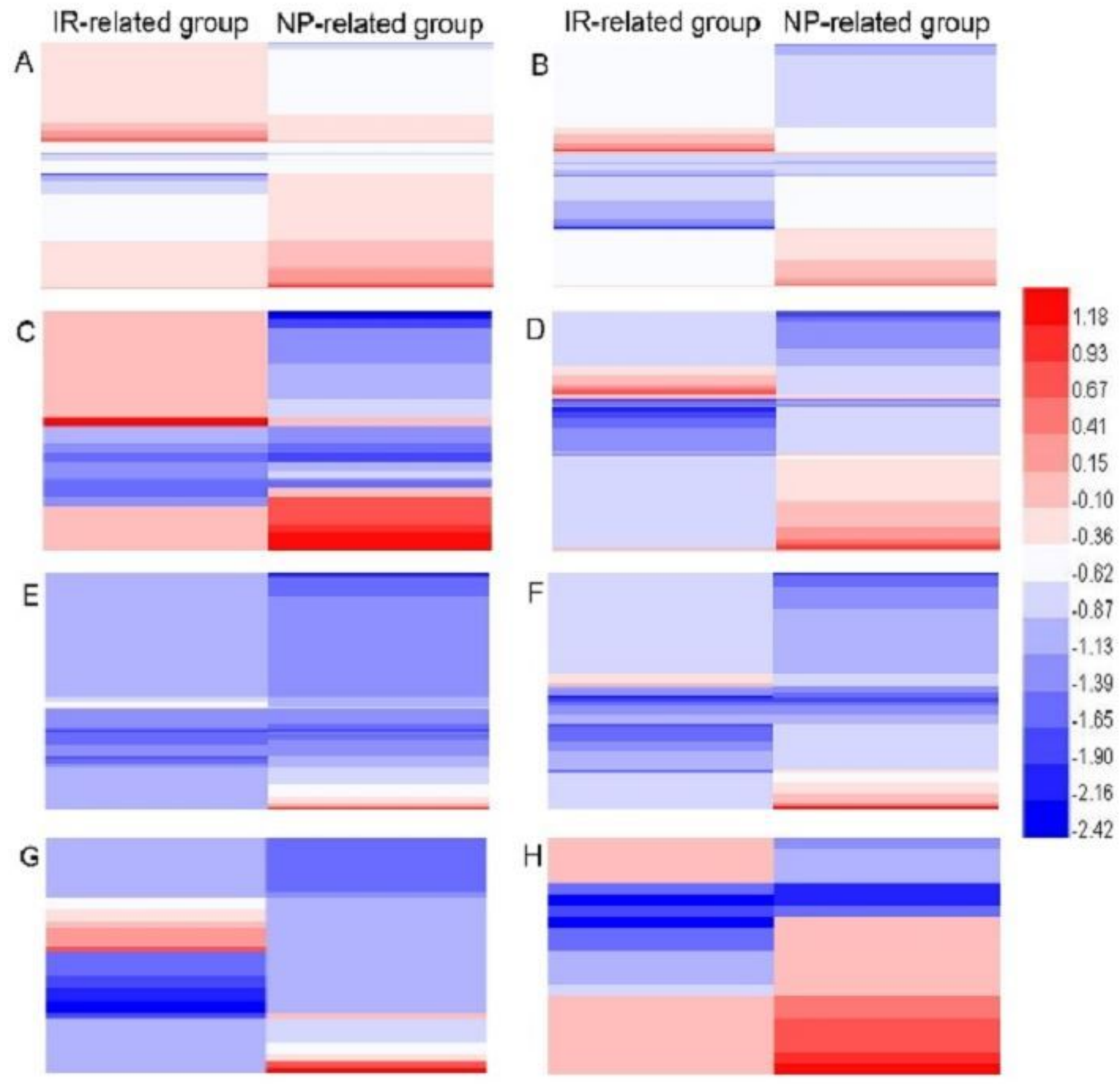

Figure 4

Expression pattern was represented by the heat map profile of IR-related group (resistance) versus NPrelated group (pathogenicity). Color changes show the level of gene expression in their respective clusters. Red, highly expressed genes; blue, highly suppressed genes. The clusters are genes for (A) defense-related response, (B) signal transduction, (C) cell death, (D) transcription factor, (E) oxidoreductases, $(F)$ defense enzymes activity, $(G)$ protease inhibitor, and $(H)$ phenylpropanoid metabolism. 

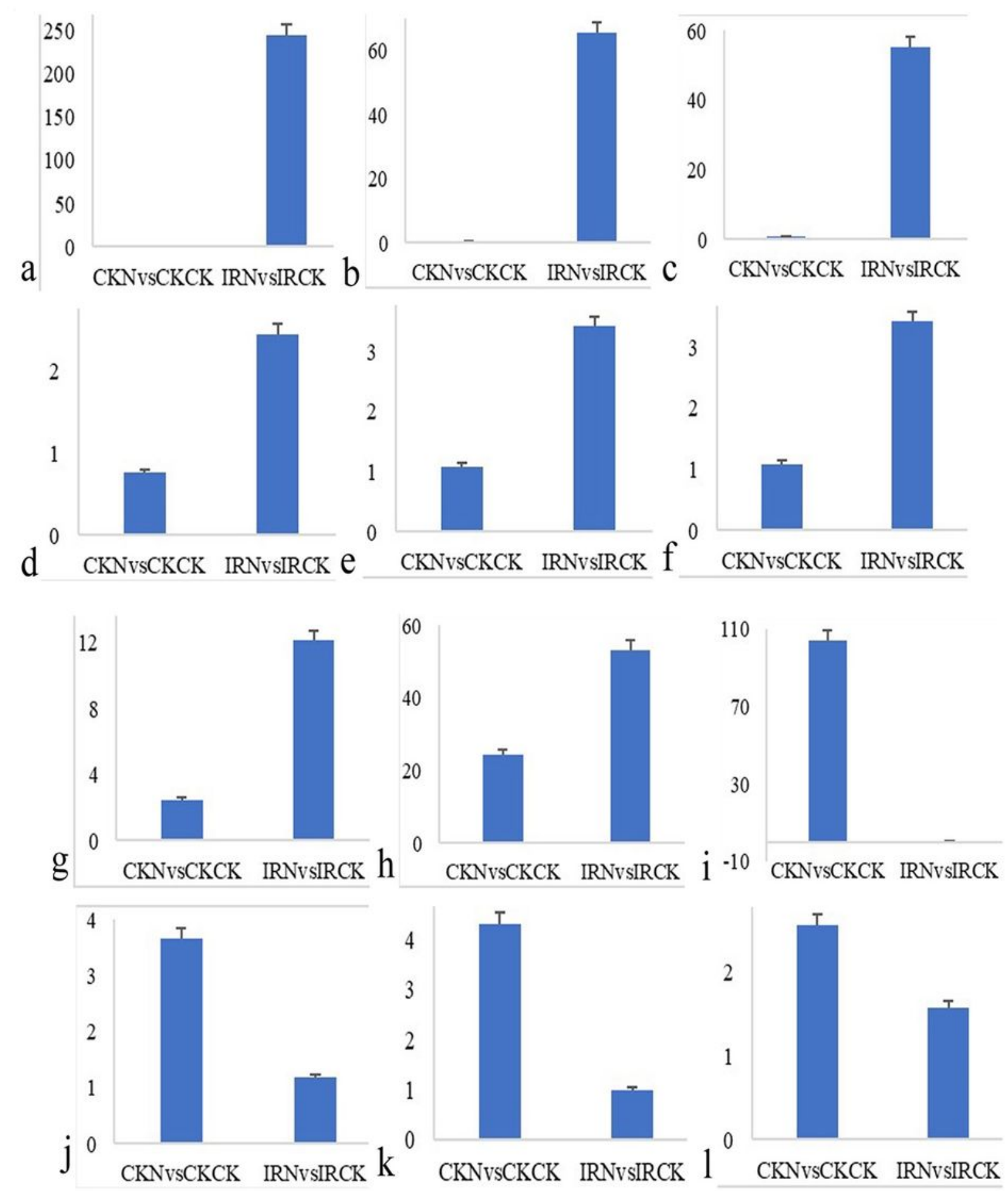

\section{Figure 5}

Validation of RNA-seq data by RT-qPCR of selected genes from tomato subjected to RKN (Meloidogyne incognita) infection with or without induction. The bars indicate relative gene expression of the control values (CKN vs CKCK) in non-induced plants with or without inoculation and the treatment values (IRN vs IRCK) in induced plants with or without inoculation, respectively. (a) myb-related protein 315-like, (b) peroxidase P7-like, (c) putative disease resistance protein RGA4, (d) disease resistance protein RPP13- 
like, (e) auxin-responsive protein IAA, (f) $15.4 \mathrm{kDa}$ class $\mathrm{V}$ heat shock protein, (g) apoptosis-inducing factor homolog A-like, (h) extra-large guanine nucleotide-binding protein 1-like, (i) protein BREAST CANCER SUSCEPTIBILITY 1 homolog, (j) peroxidase 3, (k) probable glycosyltransferase At3g07620, (I) transcription factor MYB48.
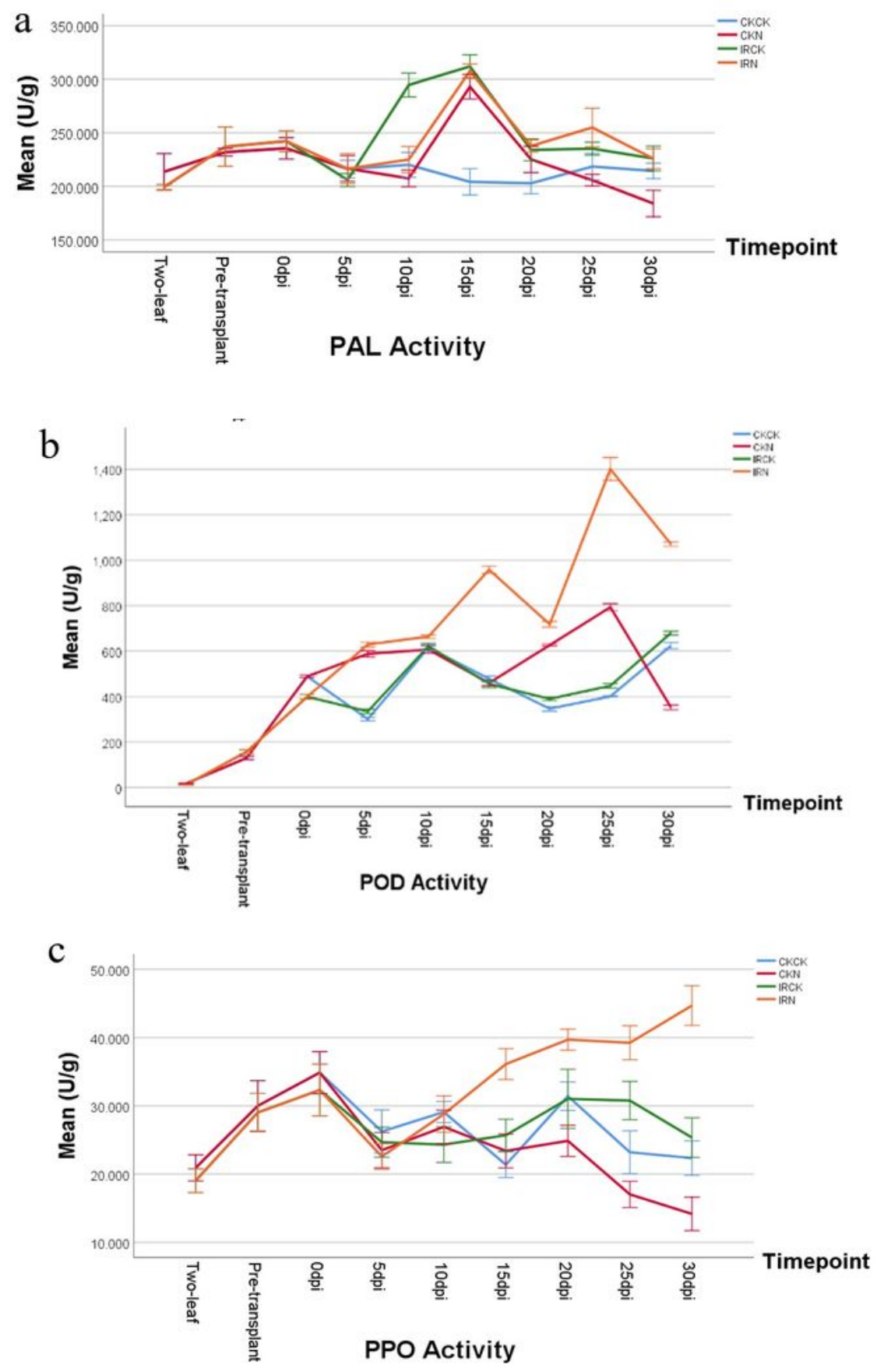

Figure 6 
The activities of different enzymes, as measured in the crude extract prepared from roots harvested at various stages after M. incognita inoculation in Snef1216 induced plants (IRN), were compared with those in non-induced plants [1] and their respective mock-inoculated controls (IRCK and CKCK). (a)

phenylalanine ammonia lyase (PAL), (b) Peroxidase [4], (c) polyphenol oxidase (PPO). Bars indicate the standard error at $\mathrm{P}$-value $=0.05$.

\section{Supplementary Files}

This is a list of supplementary files associated with this preprint. Click to download.

- SupplementaryTableS1.Inducedresistancerelatedgroups.xlsx

- SupplementaryTableS2.Nematodepathogenesisrelated.xlsx

- SupplementaryTableS3.Basalresistancerelatedgroups.xlsx

- SupplementaryTableS4.Hierarchicalclusteranalysis.xlsx

- SupplementaryTableS5.PrimersusedinRTqPCRvalidation.docx 